\title{
BUT IS IT MYOPIA? RISK AVERSION AND THE EFFICIENCY OF STOCK-BASED \\ MANAGERIAL INCENTIVES
}

\author{
JONATHAN CARMEL \\ Ross School of Business \\ University of Michigan \\ 701 Tappan \\ Ann Arbor, MI 48109-1234 \\ and \\ The Interdisciplinary Center, Herzlia \\ jpcarmel@umich.edu
}

This paper points out that stock incentives do not lead to myopia unless they result in more emphasis on the short-term than would occur under an optimal contract. It shows that myopia findings relative to the standard used throughout the literature (first-best efficiency) are often reversed when evaluated relative to the relevant standard of optimal contracting. Results reported by the previous literature to be myopia often in fact have excessive emphasis on the long-term. The paper solves in closed-form for the region in parameter space which gives rise to these reversals and shows that it can be arbitrarily large.

\section{INTRODUCTION}

Although there has been much important work on corporate myopia, ${ }_{1}$ the papers in this area share two related features whose importance has been overlooked by the literature:

(i) Managers are assumed to be risk neutral.

(ii) Myopia is evaluated relative to a first-best standard.

Although the current paper does develop a new model of myopia, this is not the paper's primary contribution. Instead the paper's primary contribution is to show that myopia findings relative to a first-best standard that ignore risk aversion are often reversed when evaluated relative

This paper is an extension of the unpublished working paper "Managerial Myopia and the Observability of Future Cash Flows" and contains its results. I thank Yaacov Bergman, Eli Berkovitch, Aaron Edlin, Ronen Israel, M.P. Narayanan, and especially Jaime Zender for their many helpful comments. All errors, of course, remain my own.

1. Narayanan (1985), Stein (1988, 1989), Thakor (1990), Bebchuk and Stole (1993), Bizjak, Brickley, and Coles (1993), Thakor (1993), and Narayanan (1996) are some important examples.

(C) 2008, The Author(s)

Journal Compilation (C) 2008 Blackwell Publishing

Journal of Economics \& Management Strategy, Volume 17, Number 2, Summer 2008, 541-579 
to the relevant standard of optimal contracting. Results purported to be myopia in the previous literature often are not and instead have excessive emphasis on the long-term. This should give pause to those who advocate governmental intervention to address this issue. Similarly, the results in Stein (1989) change from myopia to optimality when incentives are evaluated relative to an optimal-contracting standard.

The papers in the existing literature compare equilibrium outcomes to first-best outcomes in order to judge the efficiency of stockbased incentives and to determine whether stock market incentives induce myopic behavior. However, all of these models employ other market imperfections. Thus it is unclear whether the myopic behavior found in these models is due to stock-based incentives or the other market imperfections in the models. These papers also uniformly assume the manager to be risk neutral. However, typically managers are very small in terms of their wealth relative to most large corporations. They would demand an exorbitant risk premium if forced to absorb all the potential losses of the corporations they manage. Expressing payoffs in units that are meaningful for large corporations, managerial utility functions are extremely risk averse to fluctuations in corporate value. Thus it would not be optimal to try to implement first-best actions in these environments: this would create a highly inefficient allocation of risk. The only proper criterion for efficiency is second-best efficiency. The proper comparison is to the actions that could have been implemented under an optimal contract.

This paper extends the current literature by deriving the optimal contract, given the market imperfections in the model, and compares incentives for myopic behavior under stock market incentives to the behavior induced by the other market imperfections under the optimal (second-best) contract. Modeling managers as risk averse and using a second-best welfare criterion complicates the analysis. However, we are able to apply the techniques developed in Banker and Datar (1989) to derive the characteristics of the optimal contract with risk averse management and determine the extent to which myopic behavior is induced by stock market incentives.

It would be natural to assume that judging myopia results relative to a second-best optimal-contracting standard, rather than first-best, is a technical point which would have no effect on the qualitative nature of overall results. However, this paper shows that this is not the case. Moving from an irrelevant first-best standard to the proper second-best standard often reverses conclusions: What was originally thought to be myopia may in fact be excessive emphasis on the long term!

The current paper does not just give examples of such reversals. It solves in closed-form for the region in parameter space which gives 
rise to the reversals, shows that this region can be arbitrarily large, and solves for the parameters that determine the size of the region in which these reversals occur. These are the paper's main contributions.

The intuition behind these reversals comes from the tension between (i) optimal risk sharing and (ii) the incentives required to implement first-best actions. A manager has much lower risk tolerance than a large corporation. Thus there are risk-sharing benefits to emphasizing the more predictable components of firm value in managerial compensation. First-best incentives ignore these risk-sharing benefits. In the typical case in which near-term projects are less uncertain than long-term projects, optimal contracting incentives will cause the manager to give more emphasis to short-term projects than would occur under first-best incentives. Stock incentives can be properly viewed as inducing myopia only if they result in greater emphasis on short-term projects than would occur under the optimal contract. This paper shows that the risksharing benefits from emphasizing short-term projects in managerial compensation can play a large role in optimal contacting, and, for a sizeable range of parameter values, reverse myopia findings based on a first-best standard.

The paper is organized as follows. Section 2 describes the model. Section 3 characterizes behavior under stock market incentives. Section 4 examines behavior under optimal contracting. Section 5 solves for the region in which first-best and optimal-contracting standards lead to differing conclusions with respect to myopia. Section 6 discusses the paper's bearing on the Jensen-Stein myopia debate. Section 7 describes the paper's policy and empirical implications. Section 8 reviews the literature. The paper concludes with Section 9.

\section{THE MODEL}

The model assumes that the stock market cannot perfectly predict the firm's future cash flows. Instead the market can only observe the firm's future cash flows with measurement error. The stock market is completely rational and efficient in that the market value of the firm is the present value of the firm's cash flows given all information available to the market. ${ }^{2}$ The basic idea is as follows: the firm will only receive a higher stock price today for boosting a future cash flow to the extent that the market can observe today that the future cash flow will indeed increase.

2. If one allows the stock market to be inefficient, then it is quite simple to derive myopia results. So, following the standard in this literature, we only consider the harder case in which stock pricing is efficient. In fact, in this paper, the stock market is strong-form efficient. 
Consider the typical case in which the stock market can estimate the firm's near-term cash flows more precisely than the firm's long-term cash flows. If the manager could costlessly transfer a dollar of cash flow from the long-term to the short-term, it would increase its stock price today beyond that called for by the time-value of money. The reason for this is that the stock market can only estimate the firm's distant cash flows very imprecisely. Thus, the market will see very clearly that the firm's near-term cash flows have increased but will not be able to detect very precisely that the firm's long-term cash flows have decreased. The precise information that the firm's near-term cash flow has increased will cause the current stock price to move up by more than the extent to which the stock price will decrease due to the hazy information that a future cash flow may have decreased. Thus a manager acting to maximize current stock price would be willing to transfer cash flows from the long-term to the short-term at a greater ratio than called for by the discount factor.

The model examines a setting in which the firm finds it necessary to pay the manager as a function of the current stock price due to a moral hazard problem. The model is based on Bresnahan et al. (1992) and Paul (1992). Milgrom and Roberts (1992) use a very similar model to examine stock-based myopia. However as will be seen below, the present paper's conclusions differ greatly from those in Milgrom and Roberts' treatment.

The firm consists of two projects: Project 1 is a near-term project; its cash inflows will occur in Period 1. Project 2 is a long-term project; its cash inflows will occur in Period 2. At time 0 , the manager allocates an unobservable resource (such as effort) to each project. ${ }^{3}$ Let $x_{1}$ be the amount allocated to Project 1 and $x_{2}$ be the amount allocated to Project 2 . Because the allocations $x_{1}$ and $x_{2}$ are unobservable, the firm has a moral hazard problem. The manager has a preferred alternative use for the resource and so bears a private cost $V(x)$ from the resource allocation where $x=x_{1}+x_{2}$. The product of the stochastic discount factor and the realized value of the cash flow from project $t$ and is

$C_{t}=f_{t}\left(x_{t}\right)+\theta_{t} \quad t=1,2$,

where $f_{t}\left(x_{t}\right)$ is the component of the period $t$ cash flow that results from the resource allocation, and $\theta_{t}$ is a random shock that affects the cash flows in period $t$.

The variables $x_{1}, x_{2}, x, \theta_{1}, \theta_{2}$, and the cash flows $C_{1}$ and $C_{2}$ are all unobservable at time 0 . However there are informed investors in the

3. Unlike Narayanan (1985) and Stein (1989), the manager's type is known, only the resource allocation is unobservable. 
stock market who observe $Y_{1}$ and $Y_{2}$ where $Y_{t}$ is a measurement of the cash flows from project $t$.

$Y_{1}=C_{1}+\varepsilon_{1} \quad Y_{2}=C_{2}+\varepsilon_{2}$

$\varepsilon_{1}$ and $\varepsilon_{2}$ are measurement errors that are independent of the payoffs $C_{1}$ and $C_{2}$.

Let $\mathrm{W}$ be the manager's wage and $P$ be the stock price. The firm is financed entirely with equity. ${ }^{4}$ The stock price is determined by the following equation:

$$
P=\mathbf{E}\left[C_{1}+C_{2}-W \mid Y_{1}, Y_{2}\right] \text {. }
$$

Note that the stock market is (strong-form) efficient in that the informed investors do not make any profits from their private information; it is fully reflected in the stock price.

The firm makes the manager's wage a function of the stock price and, thereby, indirectly uses the market's information $Y_{1}$ and $Y_{2}$ to compensate the manager. Let $W(P)$ be the manager's wage function. We will require $W(P)$ to be nondecreasing. Otherwise the manager would have the perverse incentive to drive down the value of the firm's assets in any region in which its wage were decreasing in the stock price.

The principal reason for the use of stock-based compensation is to proxy for the terminal payoff of the firm's assets in situations in which the terminal payoff of the firm's assets cannot be observed or contracted upon. For firms with large retained earnings and firm-specific assets, the terminal value of the firm's assets cannot be observed until liquidation. For a long-lived firm, this may not occur until well after the lifetime of the manager (if at all).

The manager can receive a certainty equivalent of $W_{0}$ by working elsewhere in the economy. So the firm must make the manager an offer

4. All of the paper's results hold in the case in which the firm has risk-free debt in its capital structure: Simply replace all references to the stock price with the firm's total market value (debt and equity combined) and replace all references to the firm's stock with the firm's total assets. If compensation contracts are based on the firm's market value rather than the value of its equity, the linear inference required for the model's results is preserved. The only remaining item to check is that the firm cannot increase the efficiency of contracting by writing compensation contracts that treat the market value of debt and the market value of equity separately. It is easy to confirm that contacting separately on debt values cannot increase the efficiency of contracting because the value of risk-free debt contains no information about managerial actions. Thus no information is lost by simply summing the market value of equity and the market value of debt and writing compensation contracts on this composite. If the firm has risky debt outstanding, then the market value of debt will in general contain information about managerial actions which an optimal contract is likely to treat differently from the market value of equity. When risky debt is outstanding, one must treat the analysis presented here as an approximation to the ideal results from optimal contracting. 
which leaves it with at least a certainty equivalent of $W_{0}$, or else the manager will reject the contract.

The sequence of events is as follows. The firm sets the wage contract so as to maximize the ex ante value of the firm $\mathbf{E}\left[C_{1}+C_{2}-W\right]$. The manager then unobservably allocates resource level $x_{1}$ to Project 1 (the short-term project) and $x_{2}$ to Project 2 (the long-term project). The manager does not know the realizations of any of the random variables in the model $\left(\theta_{1}, \theta_{2}, \varepsilon_{1}, \varepsilon_{2}, Y_{1}, Y_{2}\right)$ at the time it sets $x_{1}$ and $x_{2}$. Informed investors then observe signals $Y_{1}$ and $Y_{2}$ which result in a stock price of $P=\mathbf{E}\left[C_{1}+C_{2}-W \mid Y_{1}, Y_{2}\right]$, and the manager is paid $W(P)$.

Models in the myopia literature typically involve firms or managers with unknown types who engage in myopic behavior as a signaling mechanism. In the current model, the firm's characteristics are common knowledge as are the manager's. The agency issue strictly involves hidden actions in that the manager's effort levels are unobservable to outsiders and not verifiable or contractible. ${ }^{5}$

We make the following assumptions:

Assumption 1: The production functions satisfy $f_{t}^{\prime}>0$ and $f_{t}^{\prime \prime}<0$ with $\lim _{x_{t} \rightarrow 0} f_{t}^{\prime}=\infty$ and $\lim _{x_{t} \rightarrow \infty} f_{t}^{\prime}=0$ for $t=1,2$.

Assumption 2: The manager's utility is $U(W)-V(x)$ with $U^{\prime}>0, U^{\prime \prime}<$ $0, V^{\prime}>0$, and $V^{\prime \prime}>0$.

Assumption 3: The random vector $\left(\theta_{1}, \theta_{2}, \varepsilon_{1}, \varepsilon_{2}\right)$ is joint normal. The measurement errors $\varepsilon_{1}$ and $\varepsilon_{2}$ are mutually independent and are independent of both $\theta_{1}$ and $\theta_{2} . \varepsilon_{t} \sim N\left(0, \omega_{t}^{2}\right)$ and

$\mathbf{E}\left[\begin{array}{l}\theta_{1} \\ \theta_{2}\end{array}\right]=\left[\begin{array}{l}0 \\ 0\end{array}\right] \quad \operatorname{Var}\left[\begin{array}{l}\theta_{1} \\ \theta_{2}\end{array}\right]=\left[\begin{array}{cc}\sigma_{1}^{2} & \rho \sigma_{1} \sigma_{2} \\ \rho \sigma_{1} \sigma_{2} & \sigma_{2}^{2}\end{array}\right]$

where $\rho$ is the correlation between $\theta_{1}$ and $\theta_{2}$.

Note that Assumption 3 allows the variables $\theta_{1}$ and $\theta_{2}$ to have any arbitrary correlation $\rho$. This contrasts with Paul (1992) which required the random variables analogous to $\theta_{1}$ and $\theta_{2}$ to be independent.

This model makes minimal assumptions about the manager's utility function, the firm's technology, and the shocks to the firm's

5. Milgrom and Roberts (1992) and the Bebchuk and Stole (1993) myopia models also involve hidden actions with no hidden types. (Bebchuk and Stole (1993) actually contains two models. The model which finds myopia involves hidden actions and known types. The model which finds excessive emphasis on the long-term involves visible actions and hidden types.) 
cash flows. In particular, we will be able to consider the case in which there is no permanent component to the shocks to the firm's cash flows $(\rho=0)$.

\section{INCENTIVES With STOCK-BASED COMPENSATION}

In this section we look at how stock price incentives affect the resource allocation between the short-term and long-term projects. First, however, we must solve for the stock market pricing equation. Because $\left(C_{1}\right.$, $\left.C_{2}, Y_{1}, Y_{2}\right)$ has a joint normal distribution, the expectation $\mathbf{E}\left[C_{1}+C_{2}\right.$ $\left.\mid Y_{1}, Y_{2}\right]$ is linear in a constant and the market's measurements of the firm's future cash flows $Y_{1}$ and $Y_{2}$.

Let $\mathbf{E}\left[C_{1}+C_{2} \mid Y_{1}, Y_{2}\right]=\beta_{0}+\beta_{1} Y_{1}+\beta_{2} Y_{2}$.

The equilibrium price and the manager's wage are known constants given $Y_{1}$ and $Y_{2}$. Therefore,

$\mathbf{E}\left[W \mid Y_{1}, Y_{2}\right]=W(P)$.

Together with equation (1), this yields

$\mathbf{E}\left[C_{1}+C_{2}-W \mid Y_{1}, Y_{2}\right]=\beta_{0}+\beta_{1} Y_{1}+\beta_{2} Y_{2}-W(P)$.

Because $\mathbf{E}\left[C_{1}+C_{2}-W \mid Y_{1}, Y_{2}\right]=P$, this reduces to $P+W(P)=\beta_{0}+\beta_{1} Y_{1}+\beta_{2} Y_{2}$.

Let $T(P)=P+W(P)$. Because $W(P)$ is nondecreasing, $T(P)$ is strictly increasing in $P$ and, therefore, invertible.

$P=T^{-1}\left(\beta_{0}+\beta_{1} \Upsilon_{1}+\beta_{2} \Upsilon_{2}\right)$

wage $=W\left(T^{-1}\left(\beta_{0}+\beta_{1} Y_{1}+\beta_{2} \Upsilon_{2}\right)\right)$.

\subsection{Resource allocation}

In this subsection, we examine the manager's incentives to allocate resources to the near-term and long-term projects. We can break the manager's decision down into two parts:

PRoblem 1: For any given total resource level $x$, maximize

$\operatorname{EU}\left(W\left(T^{-1}\left(\beta_{0}+\beta_{1} Y_{1}+\beta_{2} Y_{2}\right)\right)\right)$ with respect to $x_{1}$

with $x_{2}$ set equal to $x-x_{1}$.

Let $\psi(x)$ be the maximized value of $\operatorname{EU}\left(W\left(T^{-1}\left(\beta_{0}+\beta_{1} Y_{1}+\beta_{2} Y_{2}\right)\right)\right)$ found in Problem 1. 
Problem 2: Maximize $\psi(x)-V(x)$ with respect to $x$.

The solution to Problem 1 determines the manager's relative incentives to allocate resources to Project 1 versus Project 2 . Thus, only Problem 1 is relevant for an analysis of the manager's incentives to behave myopically. In Problem 1, the manager chooses $x_{1}$ so as to maximize

$\mathbf{E} U\left(W\left(T^{-1}\left(\beta_{0}+\beta_{1} Y_{1}+\beta_{2} Y_{2}\right)\right)\right)$

with $x_{2}$ set equal to $x-x_{1}$. Note that $x_{1}$ only affects $\beta_{0}+\beta_{1} Y_{1}+$ $\beta_{2} Y_{2}$ through its effect on $\beta_{1} f_{1}\left(x_{1}\right)+\beta_{2} f_{2}\left(x-x_{1}\right)$ and that $\beta_{0}+$ $\beta_{1} Y_{1}+\beta_{2} Y_{2}$ is increasing in $\beta_{1} f_{1}\left(x_{1}\right)+\beta_{2} f_{2}\left(x-x_{1}\right)$ in terms of first order stochastic dominance. Therefore, because $U, W$ and $T^{-1}$ are increasing, the manager's objective in Problem 1 is equivalent to maximizing

$\beta_{1} f_{1}\left(x_{1}\right)+\beta_{2} f_{2}\left(x-x_{1}\right)$

with respect to $x_{1}$. This objective is concave in $x_{1}$. From the first-order condition, we have that, under stock-based compensation, the manager will set $x_{1}$ such that

$\beta_{1} f_{1}^{\prime}=\beta_{2} f_{2}^{\prime}$

where

$\beta_{1}=\frac{\sigma_{1}^{2}\left(\sigma_{2}^{2}+\omega_{2}^{2}\right)-\rho \sigma_{1} \sigma_{2}\left(\rho \sigma_{1} \sigma_{2}-\omega_{2}^{2}\right)}{\left(\sigma_{1}^{2}+\omega_{1}^{2}\right)\left(\sigma_{2}^{2}+\omega_{2}^{2}\right)-\rho^{2} \sigma_{1}^{2} \sigma_{2}^{2}}$

$\beta_{2}=\frac{\sigma_{2}^{2}\left(\sigma_{1}^{2}+\omega_{1}^{2}\right)-\rho \sigma_{1} \sigma_{2}\left(\rho \sigma_{1} \sigma_{2}-\omega_{1}^{2}\right)}{\left(\sigma_{1}^{2}+\omega_{1}^{2}\right)\left(\sigma_{2}^{2}+\omega_{2}^{2}\right)-\rho^{2} \sigma_{1}^{2} \sigma_{2}^{2}}$.

Investors understand the manager's incentive problem and can solve for the resource allocations it will choose in equilibrium. Thus although investors cannot observe $x_{1}$ and $x_{2}$, they have rational expectations and understand that $x_{1}$ and $x_{2}$ will be set to their equilibrium values. Therefore, investors take $x_{1}$ and $x_{2}$ to be known constants and $x_{1}$ and $x_{2}$ do not affect the expressions for $\beta_{1}$ and $\beta_{2}$ given above. (Also see Stein, 1989; Paul, 1992.)

The closed-form expressions for $\beta_{1}$ and $\beta_{2}$ are unwieldy. However, they are simply the coefficients from the projection of $C_{1}+C_{2}$ on $Y_{1}$ and $Y_{2}$ when we allow for correlation between $\theta_{1}$ and $\theta_{2}{ }^{6}$ Intuitively, these beta formulas are exactly the large-sample regression formulas for OLS regression where the LHS sample data has the same distribution as

6. Raiffa and Schlaifer (1961). 
$C_{1}+C_{1}$ and the data for the RHS variables have the same distributions as $Y_{1}$ and $Y_{2}$.

Equation (3) determines the extent to which the manager will allocate resources to the long-term project versus the short-term project. In order to determine the efficiency of these incentives and whether they induce myopic behavior (or excessive emphasis on long-term projects), we need to solve for the allocation of resources under optimal contracting. This is discussed in Section 4.

\section{The Second-Best Solution}

The predominate standard used in the myopia literature to judge the efficiency of stock-based incentives to guide intertemporal resource allocation has been first-best efficiency. However first-best efficiency may not be the relevant criterion. In all the models in this literature, the firm faces some agency problem or other market imperfection. Even if stock market incentives were able to implement the optimal contract to deal with this market imperfection, it could still only obtain secondbest efficiency. In the current paper, for instance, the firm suffers from a moral hazard problem and thus would not be able to achieve the firstbest outcome even if it could contract directly on the stock market's information $Y_{1}$ and $Y_{2}{ }^{7}$ In order to isolate the inefficiencies due to the use of stock-based incentives, we now solve for the optimal contracting solution in which the firm can contract directly on the stock market's information $Y_{1}$ and $Y_{2}$ and use this as our benchmark with which to judge efficiency. ${ }^{8}$

In this benchmark case, the firm would want to pick a wage function $W\left(Y_{1}, Y_{2}\right)$ and effort levels $x_{1}$ and $x_{2}$ so as to maximize

$\mathbf{E}\left[C_{1}+C_{2}-W\left(Y_{1}, Y_{2}\right) \mid x_{1}, x_{2}\right]$

subject to

7. In the moral hazard model, the only way to get the resource allocation to the fullinformation, first-best level is to hire the manager with an incentive contract such that the manager will find it in its self-interest to choose the first-best allocation. Unfortunately, such a contract will place excessive risk on the risk-averse manager. At the first-best allocation, the marginal benefit of reducing the manager's risk premium will, in general, be greater than the marginal cost of reduced output caused by moving away from the first-best allocation. Thus the second-best contract, which recognizes that the manager's risk premium is a function of the specified allocation, will call for a different allocation than the first-best contract.

8. This will control for the inefficiencies due merely to the resource allocations being unobservable. 
$\mathbf{E}\left[U\left(W\left(Y_{1}, Y_{2}\right)\right) \mid x_{1}, x_{2}\right]-V\left(x_{1}+x_{2}\right)$

$$
\geq \mathrm{E}\left[U\left(W\left(Y_{1}, Y_{2}\right)\right) \mid x_{1}^{\prime}, x_{2}^{\prime}\right]-V\left(x_{1}^{\prime}+x_{2}^{\prime}\right) \text { for all }\left(x_{1}^{\prime}, x_{2}^{\prime}\right) \neq\left(x_{1}, x_{2}\right)
$$

$\mathrm{E}\left[U\left(W\left(Y_{1}, Y_{2}\right)\right) \mid x_{1}, x_{2}\right]-V\left(x_{1}+x_{2}\right) \geq U\left(W_{0}\right)$.

Constraint $(5 b)$ is the incentive compatibility constraint which requires that the manager find it in its self-interest to pick $\left(x_{1}, x_{2}\right)$ when faced with wage contract $W\left(Y_{1}, Y_{2}\right)$.

Constraint (5c) is the participation constraint that says that, with wage function $W\left(Y_{1}, Y_{2}\right)$, the manager is willing to accept the contract rather than take the certain payoff $W_{0}$ elsewhere.

Recognizing the risk aversion of the manager and the secondbest nature of optimal contracting severely complicates the analysis. However, the tools developed in Banker and Datar (1989) allow us to handle these issues. To use the results in Banker and Datar (1989), we make two additional assumptions in this section:

Assumption 4: $\quad \underline{w} \leq W \leq \bar{w}$. There are real constants $\underline{w}$ and $\bar{w}$ such that manager's wage is bounded by $\underline{w}$ from below and $\bar{w}$ from above.

This analysis holds for all finite values of $\underline{w}$ and $\bar{w}$, no matter how extreme. So this assumption does not limit the applicability of the theory in any serious way.

Assumption 5: The first-order approach to solving (5a)-(5c) is valid.

This will hold if the cost of effort function $\mathrm{V}$ is sufficiently convex or if the production functions $f_{1}$ and $f_{2}$ are sufficiently concave. Alternatively, see Jewitt (1988) for sufficient conditions to apply the first-order approach.

Under these conditions, Banker and Datar (1989) show that the optimal wage function will have the following separable form: ${ }^{9}$

$W\left(Y_{1}, Y_{2}\right)=w\left(\alpha_{1} Y_{1}+\alpha_{2} Y_{2}\right)$,

where

$\alpha_{1}=\frac{\mu_{1} f_{1}^{\prime}-\rho \mu_{2} \frac{\sigma_{1} \sigma_{2}}{\operatorname{Var}\left(Y_{2}\right)} f_{2}^{\prime}}{\operatorname{Var}\left(Y_{1}\right)}$ and $\alpha_{2}=\frac{\mu_{2} f_{2}^{\prime}-\rho \mu_{1} \frac{\sigma_{1} \sigma_{2}}{\operatorname{Var}\left(Y_{1}\right)} f_{1}^{\prime}}{\operatorname{Var}\left(Y_{2}\right)}$ and $w^{\prime}>0$

with $\quad \mu_{1}=\left(1-w^{\prime} \alpha_{1}\right) f_{1}^{\prime}$ and $\mu_{2}=\left(1-w^{\prime} \alpha_{2}\right) f_{2}^{\prime}$.

9. In the equation below, $\operatorname{Var}\left(Y_{1}\right), \operatorname{Var}\left(Y_{2}\right), \sigma_{1}, \sigma_{2}$, and $\rho$ are exogenous parameters and $\alpha_{1}, \alpha_{2}, \mu_{1}, \mu_{2}, f_{1}^{\prime}, f_{2}^{\prime}$, and $w^{\prime}$ are endogenous to the system. Also note that wage function $w$ may be nonlinear. 
The optimal contract forms a linear aggregate of $Y_{1}$ and $Y_{2}$ with loading $\alpha_{1}$ on $Y_{1}$ and loading $\alpha_{2}$ on $Y_{2}$ and then makes the manager's compensation a (possibly nonlinear) function of this linear aggregate. The constant $\mu_{t}$ is proportional to the Lagrange multiplier that measures the importance of the incentive compatibility constraint on $x_{t}$ in the principal's programming problem. ${ }^{10}$ Here we see that the loading on information about project $t$ in the (second-best) optimal contract will be:

(i) Increasing in the marginal value to the principal of the resource in the project $\left(\mu_{t} f_{t}^{\prime}\right)$.

(ii) Decreasing in the extent to which marginal value of the resource is also reflected in the signal about the other activity. (Note that $\frac{d \mathrm{E}\left[Y_{t} \mid Y_{t}^{\prime}\right]}{d Y_{t^{\prime}}}=\frac{\rho \sigma_{1} \sigma_{2}}{\operatorname{Var}\left(Y_{t}\right)}$.)

(iii) Decreasing in the imprecision of $Y_{t}$ as a measure of the resources allocated to the project $\left(\operatorname{Var}\left(Y_{t}\right)\right)$.

Equation (6) represents a major methodological break with Paul (1992). Paul (1992) requires a Holmstrom-Milgrom (1987) environment to ensure that linear contracts are optimal and solves for the optimal contract in the space of linear contracts. The current model instead makes Assumptions 1-5 which Banker and Datar (1989) show is sufficient for the optimal contract to have the separable form described in equation (6). This analysis implies that Assumptions 1-5 can be used to extend the results of Paul (1992) outside of a Holmstrom-Milgrom (1987) environment. $\alpha_{2}:{ }^{12}$

After some algebra, ${ }_{11}^{11}$ we obtain the following solutions for $\alpha_{1}$ and

$\alpha_{1}=\frac{G_{2} \frac{\left(f_{1}^{\prime}\right)^{2}}{\operatorname{Var}\left(Y_{1}\right)}-D\left(f_{2}^{\prime}\right)^{2}}{\left(1+E_{1}\right)\left(1+E_{2}\right)-\rho \sigma_{1} \sigma_{2} D E_{1} E_{2}}$

$\alpha_{2}=\frac{G_{1} \frac{\left(f_{2}^{\prime}\right)^{2}}{\operatorname{Var}\left(Y_{2}\right)}-D\left(f_{1}^{\prime}\right)^{2}}{\left(1+E_{1}\right)\left(1+E_{2}\right)-\rho \sigma_{1} \sigma_{2} D E_{1} E_{2}}$,

where

$D=\frac{\rho \sigma_{1} \sigma_{2}}{\operatorname{Var}\left(Y_{1}\right) \operatorname{Var}\left(Y_{2}\right)} \quad E_{t}=\frac{w^{\prime}\left(f_{t}^{\prime}\right)^{2}}{\operatorname{Var}\left(Y_{t}\right)} \quad G_{t}=\left(1+E_{t}\right)-\rho \sigma_{1} \sigma_{2} D E_{t}$.

10. Differentiating (5b) with respect to $x_{1}$ gives us the incentive compatibility constraint on $x_{1} . \mu_{1} / V^{\prime \prime}$ is the Lagrange multiplier on this constraint. Differentiating $(5 \mathrm{~b})$ with respect to $x_{2}$ gives us the other incentive compatibility constraint. $\mu_{2} / V^{\prime \prime}$ is its Lagrange multiplier.

11. The algebra is available from the author upon request.

12. In the equation below, only $f_{1}^{\prime}, f_{2}^{\prime}$, and $w^{\prime}$ are endogenous to the system. 


\subsection{INTERTEMPORAL INCENTIVES AT THE SECOND-BEST OPTIMUM}

In order to determine the resource allocation at the second-best optimum, we once again break the manager's decision down into two parts:

РRoвlem 1: For any given total resource level $x$, maximize

$\mathbf{E U}\left(w\left(\alpha_{1} Y_{1}+\alpha_{2} Y_{2}\right)\right)$ with respect to $x_{1}$ with $x_{2}$ set equal to $x-x_{1}$.

Let $\varphi(x)$ be the maximized value of $\operatorname{EU}\left(w\left(\alpha_{1} Y_{1}+\alpha_{2} Y_{2}\right)\right)$ found in Problem 1.

Problem 2: Maximize $\varphi(x)-V(x)$ with respect to $x$.

As in Section 3, the solution to Problem 1 determines the manager's relative incentives to allocate resources to Project 1 versus Project 2. Thus, Problem 1 determines the manager's intertemporal incentives under the (second-best) optimal contract. In Problem 1, the manager chooses $x_{1}$ so as to maximize

$\mathbf{E} U\left(w\left(\alpha_{1} Y_{1}+\alpha_{2} Y_{2}\right)\right)$,

where $x_{2}$ equals to $x-x_{1}$. Once again, note that $x_{1}$ only affects $\alpha_{1} Y_{1}+$ $\alpha_{2} Y_{2}$ through its effect on $\alpha_{1} f_{1}\left(x_{1}\right)+\alpha_{2} f_{2}\left(x-x_{1}\right)$ and that $\alpha_{1} Y_{1}+\alpha_{2} Y_{2}$ is increasing in $\alpha_{1} f_{1}\left(x_{1}\right)+\alpha_{2} f_{2}\left(x-x_{1}\right)$ in terms of first-order stochastic dominance. Therefore, because $U$ and $w$ are increasing, the manager's objective in Problem 1 is equivalent to maximizing

$\alpha_{1} f_{1}\left(x_{1}\right)+\alpha_{2} f_{2}\left(x-x_{1}\right)$

with respect to $x_{1}$. This objective is concave in $x_{1}$. From the first-order condition, the second-best solution requires that $x_{1}$ be set so that ${ }^{13}$

$\alpha_{1} f_{1}^{\prime}=\alpha_{2} f_{2}^{\prime}$.

However, from equation (3), stock-based incentives lead the firm to set $x_{1}$ so that

$\beta_{1} f_{1}^{\prime}=\beta_{2} f_{2}^{\prime}$.

This gives us the following two results:

(i) If $\frac{\beta_{1}}{\beta_{2}}>\frac{\alpha_{1}}{\alpha_{2}}$, then the manager will overemphasize the short-term project relative to second best.

13. Note that the first-best allocation of effort occurs when $f_{1}^{\prime}=f_{2}^{\prime}$. The ratio $\alpha_{1} / \alpha_{2}$ determines the extent to which the second-best resource allocation differs from the firstbest. If $\alpha_{1} / \alpha_{2}>1$, the second-best contract allocates more resources to the short-term project relative to first-best. If $\alpha_{1} / \alpha_{2}<1$, the opposite occurs. 
(ii) If $\frac{\beta_{1}}{\beta_{2}}<\frac{\alpha_{1}}{\alpha_{2}}$, then the manager will overemphasize the long-term project relative to second best.

The ratio $\beta_{1} / \beta_{2}$ measures how informative information about short-term cash flows is relative to information about long-term cash flows in determining firm value. The ratio $\alpha_{1} / \alpha_{2}$ is given by the relative importance of information about short-term versus long-term cash flows in determining the manager's marginal contribution or value-added. ${ }^{14}$

Equation (4) can also be expressed as follows:

$$
\frac{\beta_{1}}{\beta_{2}}=\frac{\frac{\sigma_{1}^{2}}{\operatorname{Var}\left(Y_{1}\right)}-\frac{\rho \sigma_{1} \sigma_{2}}{\operatorname{Var}\left(Y_{1}\right)} \frac{\rho \sigma_{1} \sigma_{2}-\omega_{2}^{2}}{\operatorname{Var}\left(Y_{2}\right)}}{\frac{\sigma_{2}^{2}}{\operatorname{Var}\left(Y_{2}\right)}-\frac{\rho \sigma_{1} \sigma_{2}}{\operatorname{Var}\left(Y_{1}\right)} \frac{\rho \sigma_{1} \sigma_{2}-\omega_{1}^{2}}{\operatorname{Var}\left(Y_{2}\right)}} .
$$

The most important case is that of large corporations in which the manager's risk tolerance is small relative to the variability of firm cash flows. The remainder of this paper will consider the limit as the manager's risk tolerance goes to zero when measured in terms of the variance of firm cash flows, implying $w^{\prime}=0 .{ }^{15}$ Thus from equation (6), $\mu_{1}$ converges to $f_{1}^{\prime}$ and $\mu_{2}$ converges to $f_{2}^{\prime}$. Substituting these values for $\mu_{1}$ and $\mu_{2}$ into equation (7) yields ${ }^{16}$

$$
\frac{\alpha_{1}}{\alpha_{2}}=\frac{\frac{\left(f_{1}^{\prime}\right)^{2}}{\operatorname{Var}\left(Y_{1}\right)}-\frac{\rho \sigma_{1} \sigma_{2}}{\operatorname{Var}\left(Y_{1}\right)} \frac{\left(f_{2}^{\prime}\right)^{2}}{\operatorname{Var}\left(Y_{2}^{\prime}\right)}}{\frac{\rho \sigma_{1} \sigma_{2}}{\operatorname{Var}\left(Y_{2}\right)}-\frac{\left(f_{1}^{\prime}\right)^{2}}{\operatorname{Var}\left(Y_{1}\right)}} \frac{\operatorname{Var}\left(Y_{2}\right)}{\operatorname{Var}}
$$

Ratios (9) and (10) have a similar structure with resource marginal productivities appearing in ratio (10) in place of information about the magnitude of the stochastic shocks to cash flows and their observability. In general, ratios (9) and (10) will not be the same.

Equation (9) solves for $\beta_{1} / \beta_{2}$ solely as a function of the variances and correlation of the model's random variables. The production functions $f_{1}$ and $f_{2}$ do not enter into the equation. Equation (10), by contrast, does require $f_{1}^{\prime}$ and $f_{2}^{\prime}$ in its characterization of $\alpha_{1} / \alpha_{2}$. Proposition 1 shows

14. Bresnahan et al. (1992) and Paul (1992) introduce the notion that the stock market weights information according to its informativeness about value while optimal incentives require information to be weighted according to its informativeness about the manager's value-added.

15. All units are in terms of the firm's cash flows. For large corporations, the variability (or steepness) of the manager's incentive schedule is trivial when measured in terms of the variability of firm's cash flows.

16. Note that $w^{\prime}=0$ implies $G_{t}=1$ in equation (7). 
that this is not necessary. The proposition determines $\alpha_{1} / \alpha_{2}$ as a function of the variance and correlation of the model's random variables $\left(\rho, \sigma_{1}\right.$, $\sigma_{2}, \omega_{1}$, and $\omega_{2}$ ) without reference to $f_{1}$ or $f_{2}$. The proposition shows that $\alpha_{1} / \alpha_{2}$ satisfies a cubic polynomial equation. Accordingly, it can be expressed in closed-form.

Proposition 1: The ratio $\alpha_{1} / \alpha_{2}$ satisfies the following cubic equation:

$\left(\frac{\alpha_{1}}{\alpha_{2}}\right)^{3}+\kappa\left(\frac{\alpha_{1}}{\alpha_{2}}\right)^{2}-\kappa\left(\frac{\alpha_{1}}{\alpha_{2}}\right)-\frac{\operatorname{Var}\left(Y_{2}\right)}{\operatorname{Var}\left(Y_{1}\right)}=0$,

where

$\kappa=\frac{\rho \sigma_{1} \sigma_{2}}{\operatorname{Var}\left(\mathrm{Y}_{1}\right)}$.

For $\rho \geq 0$, the positive real solution to equation (11) exists and is unique. ${ }^{17}$

The proof is provided in the Appendix.

The optimal contract puts more weight on the signal which is the most precise observation of managerial allocations regardless of the value of other model parameters. From Proposition 1, for $\rho \geq 0$ :

(i) $\alpha_{1} / \alpha_{2}>1$ if and only if $\operatorname{Var}\left(Y_{2}\right) / \operatorname{Var}\left(Y_{1}\right)>1$;

(ii) $\alpha_{1} / \alpha_{2}=1$ if and only if $\operatorname{Var}\left(Y_{2}\right) / \operatorname{Var}\left(Y_{1}\right)=1$; and

(iii) $\alpha_{1} / \alpha_{2}<1$ if and only if $\operatorname{Var}\left(Y_{2}\right) / \operatorname{Var}\left(Y_{1}\right)<1$.

One would generally expect the standard deviation of the noise in the market's ability to observe future cash flows to be increasing in the cash flow's arrival date. This condition is denoted $\omega_{2}>\omega_{1}$ and creates a tendency for $\operatorname{Var}\left(Y_{2}\right)$ to be greater than $\operatorname{Var}\left(Y_{1}\right)$. In such cases, optimal contracting will appear to result in myopia, if judged relative to the first-best standard.

Because managers are risk averse, there is an advantage to overemphasizing near-term cash flows in their compensation relative to firstbest. The first-best criterion makes the unrealistic assumption that the manager and the corporation (the aggregate of all the firm's investors) are equally able to handle the risk associated with a unit of payoff variability. Once one recognizes that managers are risk averse, then, in the standard case in which the market's information about nearterm cash flows is less variable than its information about long-term cash flows, optimal contracting will naturally place more emphasis

17. For $\rho<0$, one can show that a positive real solution to equation (11) exists. However, it may not be unique. See Appendix. 
on near-term cash flows relative to overall firm value. Before one can assess whether stock-based compensation leads to myopic behavior, one has to determine whether the additional emphasis given to short-term projects is greater than it would be under optimal contracting. If not, the "myopia" is due to moral hazard, not stock incentives.

\section{FiRST-BEST VERSUS OPTIMAL CONTRACT STANDARDS: A COMPARISON}

From equations (9) and (10), it is clear that the criterion for myopic behavior relative to optimal contracting incentives, $\beta_{1} / \beta_{2}>\alpha_{1} / \alpha_{2}$, is not identical to the criterion for myopic behavior relative to first-best incentives, $\beta_{1} / \beta_{2}>1$. This section examines the regions in which these criteria lead to conflicting conclusions about the presence of myopic behavior (or excessive emphasis on long-term projects) and present comparative statics results that show the effect of model parameters on the size of the region in which the first-best and optimal contracting criteria give rise to conflicting assessments.

\subsection{AN EXAMPLE}

Before presenting a general analysis, it is helpful to consider the following example in which $\sigma_{2} / \sigma_{1}=5$ and $\sigma_{1} / \omega_{1}=5$. The ratio $\sigma_{2} / \sigma_{1}$ determines the importance of the long-term project relative to the shortterm project in determining the variable component of the firm's total cash flow. In this example, the long-term project is much more important than the short-term project in determining total cash flow. For instance the short-term project might concern decisions that pertain only to the coming quarter's cash flows while the long-term project might concern decisions relating to the firm's entire stream of future cash flows.

The ratio $\sigma_{1} / \omega_{1}$ determines how much of the uncertainty about the short-term cash flow is revealed by the signal observed by the market about the short-term cash flow $\left(Y_{1}\right)$. Suppose the manager is making decisions at the beginning of the quarter about resource allocations to the near-term and long-term projects. Further suppose that the manager will be compensated based on the end of quarter stock price. At the beginning of the quarter there might be substantial uncertainty about the cash flow of the short-term project. Yet the accounting numbers released at the end of the quarter might resolve a large amount of this uncertainty, particularly if the short-term project only relates to the current quarter's cash flow. In such cases, the signal to noise ratio $\sigma_{1} / \omega_{1}$ will be quite large. In this example we consider the case in which it is 5 . 


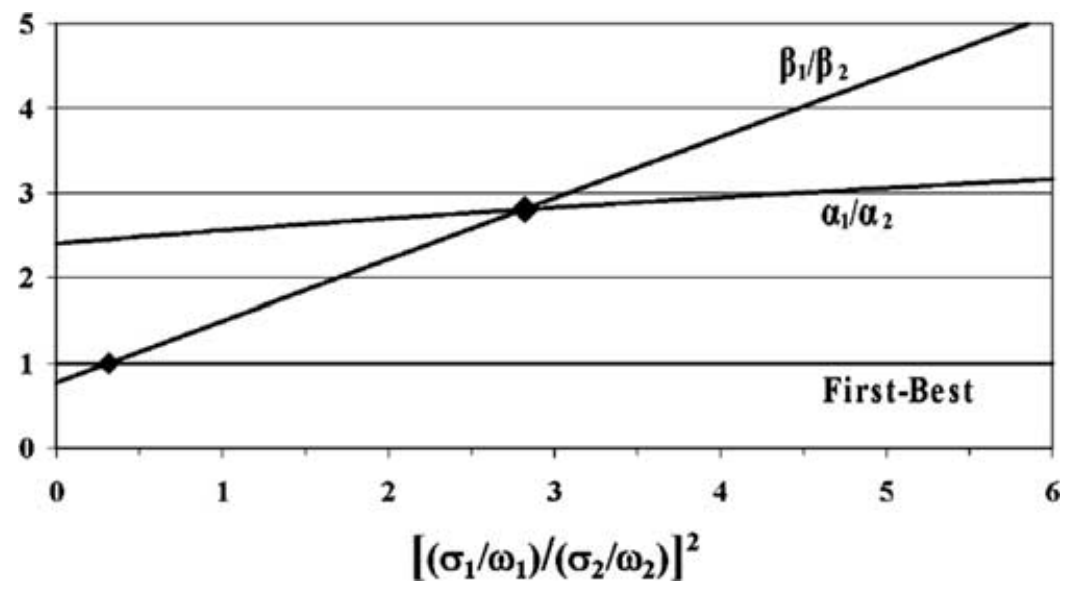

FIGURE 1. INCENTIVES AS A FUNCTION OF $\left[\left(\sigma_{1} / \omega_{1}\right) /\left(\sigma_{2} / \omega_{2}\right)\right]^{2}$ : $\sigma_{2} / \sigma_{1}=5, \sigma_{1} / \omega_{1}=5, \rho=0.5$

Figure 1 graphs $\beta_{1} / \beta_{2}$ and $\alpha_{1} / \alpha_{2}$ against the ratio of the squared signal-to-noise ratios ${ }^{18}$ of the near-term and long-term project: $\left(\sigma_{1} / \omega_{1}\right)^{2} /\left(\sigma_{2} / \omega_{2}\right)^{2}$. The correlation parameter $\rho$ is set to 0.5 . The graph of $\beta_{1} / \beta_{2}$ crosses 1 at $\left(\sigma_{1} / \omega_{1}\right)^{2} /\left(\sigma_{2} / \omega_{2}\right)^{2}$ equal to 0.31 and crosses the graph of $\alpha_{1} / \alpha_{2}$ at $\left(\sigma_{1} / \omega_{1}\right)^{2} /\left(\sigma_{2} / \omega_{2}\right)^{2}$ equal to 2.81. Note that if the squared signal-to-noise ratio of the near-term project divided by the squared signal-to-noise ratio of the long-term project is (strictly) between 0.31 and 2.81, the first-best criteria would mistakenly conclude that myopic incentives exist when, in actuality, stock-based incentives are causing excessive emphasis on the long-term project. For values of $\left(\sigma_{1} / \omega_{1}\right)^{2} /\left(\sigma_{2} / \omega_{2}\right)^{2}$ below 2.81 , stock-based incentives place excessive emphasis on the long-term project, subjecting management to excessive risk and the firm to an excessive risk premium. The first-best comparison ignores the risk premium required to employ a risk averse manager and, for all values of $\left(\sigma_{1} / \omega_{1}\right)^{2} /\left(\sigma_{2} / \omega_{2}\right)^{2}$ above 0.31 , concludes that stockbased incentives place excessive emphasis on the short-term project (myopia).

The region in which the first-best criteria mistakenly finds myopic behavior in Figure 1 is considerable: values of $\left(\sigma_{1} / \omega_{1}\right)^{2} /\left(\sigma_{2} / \omega_{2}\right)^{2}$ ranging from 0.31 and 2.81. Similarly, the proper cut-off for assessing whether $\beta_{1} / \beta_{2}$ will induce myopia can be very far from one. In Figure 1, the

18. Because the ratios $\sigma_{1} / \omega_{1}$ and $\sigma_{2} / \sigma_{1}$ are both held fixed in Figure 1 , changes in $\left(\sigma_{1} / \omega_{1}\right)^{2} /\left(\sigma_{2} / \omega_{2}\right)^{2}$ along the horizontal axis are completely determined by changes in $\omega_{2}$. Nonetheless, it is useful to normalized the values along the horizontal axis to be the ratio of the signal to noise ratios $\left(\sigma_{1} / \omega_{1}\right)^{2} /\left(\sigma_{2} / \omega_{2}\right)^{2}$, rather than $\omega_{2}^{2}$. 
$\beta_{1} / \beta_{2}$ curve crosses the $\alpha_{1} / \alpha_{2}$ curve at $\alpha_{1} / \alpha_{2}$ equal to 2.80 . The proper trigger for assessing whether $\beta_{1} / \beta_{2}$ will cause myopic behavior at the intersection point is almost three times as high as the trigger used by the first-best criterion ( 2.8 versus 1$){ }^{19}$

This example treats the typical case in which the short-term cash flows are substantially more predictable than long-term cash flows. Given that a large corporation's risk tolerance is orders of magnitudes higher than that of an individual person, optimal contracting will link managerial pay more heavily to measures of short-term cash flows than overall cash flows (holding incentive effects constant). As demonstrated in this example, this effect can be quite large and must be taken into account before one can make judgments about the role of stock incentives in generating myopia.

\subsection{GENERAL ANALYSIS}

The ratio $\left(\sigma_{1} / \omega_{1}\right)^{2} /\left(\sigma_{2} / \omega_{2}\right)^{2}$ is a measure of the relative informativeness of the market's signals about short-term versus long-term cash flows in determining overall firm value. From Section 3.1 the informativeness of the market's information about short-term cash flows relative to longterm cash flows for assessing firm value is a major determinant of $\beta_{1} / \beta_{2}$ and the manager's allocation of effort between the short-term and longterm projects. Accordingly, it will be useful to examine the behavior of $\alpha_{1} / \alpha_{2}$ and $\beta_{1} / \beta_{2}$ as a function of $\left(\sigma_{1} / \omega_{1}\right)^{2} /\left(\sigma_{2} / \omega_{2}\right)^{2}$, holding $\rho, \sigma_{2} / \sigma_{1}$, and $\sigma_{1} / \omega_{1}$ fixed. At this point, we introduce the additional notation:

$\phi=\frac{\left(\sigma_{1} / \omega_{1}\right)^{2}}{\left(\sigma_{2} / \omega_{2}\right)^{2}}$.

$b(\phi)$ determines the value of $\beta_{1} / \beta_{2}$ as a function of $\phi$, holding $\rho, \sigma_{2} / \sigma_{1}$, and $\sigma_{1} / \omega_{1}$ fixed. $a(\phi)$ determines the value of $\alpha_{1} / \alpha_{2}$ as a function of $\phi$, holding $\rho, \sigma_{2} / \sigma_{1}$, and $\sigma_{1} / \omega_{1}$ fixed. In Figure 1 , the curve labeled $\beta_{1} / \beta_{2}$ is a graph of $b(\phi)$ and the curve labeled $\alpha_{1} / \alpha_{2}$ is a graph of $a(\phi)$.

All of the important features of the curves graphed in Figure 1 are general:

1. In Figure $1, b(\phi)$ is linear in $\phi$ and strictly increasing.

Equation (9) can be re-expressed as ${ }^{20}$

$$
b(\phi)=Q+R \phi,
$$

19. The similarity between the value of $\left(\sigma_{1} / \omega_{1}\right)^{2} /\left(\sigma_{2} / \omega_{2}\right)^{2}$ at the point where $\beta_{1} / \beta_{2}$ equals $\alpha_{1} / \alpha_{2}$ (2.81) and the value of $\alpha_{1} / \alpha_{2}$ at the point where $\beta_{1} / \beta_{2}$ equals $\alpha_{1} / \alpha_{2}$ (2.80) is a coincidence. See Proposition 2.

20. The algebra is available from the author upon request. 
where

$$
\begin{aligned}
& Q=\frac{\left(1-\rho^{2}\right) \eta}{\left(1-\rho^{2}\right) \eta+\left(1+\frac{\rho}{\gamma}\right)} \quad R=\frac{(1+\rho \gamma)}{\left(1-\rho^{2}\right) \eta+\left(1+\frac{\rho}{\gamma}\right)} \\
& \gamma=\frac{\sigma_{2}}{\sigma_{1}} \quad \eta=\frac{\sigma_{1}^{2}}{\omega_{1}^{2}} .
\end{aligned}
$$

$b(\phi)$ is always linear in $\phi$. The condition $\rho \geq 0$ ensures that $b(\phi)$ is increasing in $\phi .^{21}$

2. In Figure $1, a(\phi)$ is strictly increasing in $\phi$. Applying the implicit function theorem to equation (11) generates ${ }^{22}$

$$
\frac{d a}{d \phi}=\frac{\gamma^{2} /(1+\eta)}{3 a^{2}+2 \kappa a-\kappa} \quad \gamma=\frac{\sigma_{2}}{\sigma_{1}} \quad \eta=\frac{\sigma_{1}^{2}}{\omega_{1}^{2}} .
$$

For $\rho \geq 0$, it can be shown that the expression for $d a / d \phi$ given in equation (15) is always positive. ${ }^{23}$

3. The $a(\phi)$ curve and the $b(\phi)$ curve have a single intersection. In the region between this intersection point and $b(\phi)=1$, first-best and optimal contracting criteria have conflicting findings with respect to the presence of myopia versus excessive emphasis on the long run. Proposition 2 below establishes that the $a(\phi)$ curve and the $b(\phi)$ curve have a single intersection for all cases in which $\rho \geq 0$. It also provides closed-form expressions for $\phi$ and $a(\phi)$ at the point where the $a(\phi)$ curve intersects the $b(\phi)$ curve.

4. In Figure 1, $a(\phi)$ increases in $\phi$ more slowly than $b(\phi)$. From equation (15), $a(\phi)$ is strictly concave in $\phi$ and therefore increases at less than a linear rate. However, when $\sigma_{2} / \sigma_{1}$ is large and $\sigma_{1} / \omega_{1}$ is small, there can be a region in which $a(\phi)$ increases more rapidly than $b(\phi)$. Even in these cases, the $a(\phi)$ curve will cross the $b(\phi)$ curve at a single point and $a(\phi)$ will increase more slowly than $b(\phi)$ at the intersection point. $^{24}$

21. For $b$ to be decreasing in $\phi, \rho\left(\sigma_{2} / \sigma_{1}\right)$ must be negative and have a magnitude greater than 1 or $\rho\left(\sigma_{1} / \sigma_{2}\right)$ must be negative and have a magnitude greater than $1+(1-$ $\left.\rho^{2}\right) \eta$.

22. Equation (15) is simple to derive once one observes that $\operatorname{Var}\left(Y_{2}\right) / \operatorname{Var}\left(Y_{1}\right)=\gamma^{2}(\eta+$ $\phi) /(1+\eta)$ and that $\phi$ does not enter into $\kappa$.

23. See Appendix.

24. Proposition 2 below establishes that $a(\phi)$ and $b(\phi)$ intersect at a single point. Note that $a(\phi)$ and $b(\phi)$ are strictly increasing and $b(\phi)$ is linear while $a(\phi)$ is strictly concave. This implies that $a(\phi)$ crosses $b(\phi)$ from above and therefore must have a smaller slope at the intersection point. 
5. In Figure 1, the $a(\phi)$ curve is above the $b(\phi)$ curve to the left of the intersection point, and the $a(\phi)$ curve is below the $b(\phi)$ curve to the right of the intersection point. This too is general. ${ }^{25}$

Proposition 2: Consider any fixed values of $\rho, \sigma_{2} / \sigma_{1}$, and $\sigma_{1} / \omega_{1}$ such that $\sigma_{1} / \omega_{1} \geq 0, \rho \geq 0$, and $\sigma_{2} / \sigma_{1}>0$. Let $\phi^{*}$ be the value of $\phi$ such that the $b(\phi)=a(\phi)$. The constant $\phi^{*}$ is unique and provided in equation (16b). At this value of $\phi$, the values of $\alpha_{1} / \alpha_{2}$ and $\beta_{1} / \beta_{2}$ are unique and provided in equation (16a). Denote $a^{*}$ to be the value of $\alpha_{1} / \alpha_{2}$ at the point where $b(\phi)=a(\phi)$.

$a^{*}=\gamma S^{1 / 2}$.

and

$\phi^{*}=(1+\eta) \gamma S^{3 / 2}-\eta S-\rho \eta S^{1 / 2}+\frac{\rho \eta}{\gamma}$,

where

$$
S=\frac{1+\frac{\rho}{\gamma}}{1+\rho \gamma} \quad \gamma=\frac{\sigma_{2}}{\sigma_{1}} \quad \eta=\frac{\sigma_{1}^{2}}{\omega_{1}^{2}} .
$$

These expressions are defined for all nonnegative values of $\rho$.

The proof of Proposition 2 is provided in the Appendix.

The remainder of this section maintains the assumptions of Proposition 2: $\sigma_{1} / \omega_{1} \geq 0, \rho \geq 0$, and $\sigma_{2} / \sigma_{1}>0$. From equation (16b), it is possible that the intersection between the $b(\phi)$ curve and the $a(\phi)$ curve occurs at a negative value of $\phi$. However, because squared signal-tonoise ratios cannot be negative, negative values of $\phi$ are not relevant for the model. The remainder of this section also restricts attention to values of $\rho, \sigma_{1} / \omega_{1}$, and $\sigma_{2} / \sigma_{1}$ such that the value for $\phi^{*}$ given in equation (16b) is nonnegative. ${ }^{26}$

Proposition 2 establishes that the point at which the $b(\phi)$ curve crosses the $a(\phi)$ curve is unique. Recall that $a^{*}$ is the value of $a(\phi)$ at the intersection point. Because the $b(\phi)$ curve has a unique intersection with the first-best curve ${ }^{27}$ (the horizontal line with value 1) and a

25. Proposition 2 below establishes that $a(\phi)$ and $b(\phi)$ intersect at a single point. The previous footnote established that a $(\phi)$ crosses $b(\phi)$ from above and therefore must be above $b(\phi)$ for values of $\phi$ that are less than the value at the intersection point and below $b(\phi)$ for values of $\phi$ that are greater than the value at the intersection point.

26. The following holds for parameter values such that the value of $\phi^{*}$ in equation (16b) is negative: (i) $b(\phi)>a(\phi)$ for all nonnegative values of $\phi$; (ii) stock-based incentives induce myopia occurs relative to optimal contracting for all nonnegative values of $\phi$; (iii) if $b(0)$ $>1$, then the first-best and optimal contracting criteria always agree; (iv) if $b(0)<1$, then the first-best criteria mistakenly finds excessive emphasis on the long-term project for all values of $\phi$ less than the constant $S$. The value of $S$ is given in equation (16c).

27 . The strict monotonicity of $b(\phi)$ ensures that $b(\phi)$ uniquely crosses the horizontal line with value one. 
unique intersection with the $a(\phi)$ curve, the region in which the firstbest criterion makes incorrect inferences about the presence of myopic behavior (or excessive emphasis on the long-term) is the region between $b(\phi)=1$ and $b(\phi)=a^{*}$. In Figure 1 , this is the region between the diamonds marking the points where the $b(\phi)$ curve crosses the values 1 and $a^{*}$, respectively. In terms of $\phi$, this region corresponds to values of $\phi$ between the constant $S$ and the value given in equation (16b). The value for $S$ is given in equation (16c). It is the value of $\phi$ at the point where $b(\phi)=1 .^{28}$

If $a^{*}>1$, then, for all values of $\phi$ such that $b(\phi)$ is strictly between 1 and $a^{*}$, the first-best criteria mistakenly concludes that stock incentives have caused myopic behavior when, in actuality, stock-based incentives are causing excessive emphasis on the long-term project. Here the principal-agent problem is inducing myopia, not the stock-based incentives. Although stock-based incentives help move the agent's allocation of the unobservable resource closer to the first-best level, they nonetheless reduce both overall welfare and the wealth of the principal (firm value), by placing excessive risk on the manager relative to what would occur in a optimal contract. This excessive risk requires the principal to pay an excessive risk premium to the manager. The extra risk premium required by the manager more than offsets the added value that comes from having the unobservable allocation move closer to first-best.

If $a^{*}<1$, then, for all values of $\phi$ such that $b(\phi)$ is strictly between $a^{*}$ and 1, the first-best criteria mistakenly concludes that stock incentives have caused excessive emphasis on the long-term project when in actuality stock-based incentives have induced myopia. Now it is the principal-agent problem that causes excessive concern for the long-term, not the stock-based incentives. As in the previous case, the benefits that stock-based incentives provide by moving the agent's allocation closer to first-best are not sufficient to overcome the loss in value due to diminished risk-sharing.

From the previous two paragraphs, the direction of the conflict between first-best and optimal contracting conclusions about myopia is completely determined by the relationship between $a^{*}$ and one. For $a^{*}>1$, the first-best criterion finds myopia in the region of disagreement when stock-based incentives actually cause excessive emphasis on the long-term. The opposite occurs when $a^{*}$ is less than one. For $a^{*}$ equal to one, the conclusions from first-best analysis and optimal contract

28. From equations (14a) and (14b), it is easy to establish that $S=(1-Q) / R$ which implies that $\phi=S$ at $b(\phi)=1$. 
analysis always agree about direction but will generally differ regarding the magnitude of inefficiency.

Fortunately, it is easy to determine when $a^{*}$ will be above (or below) one in this model. From equation (16a):

(i) $a^{*}>1$ if and only if $\sigma_{2} / \sigma_{1}>1$;

(ii) $a^{*}<1$ if and only if $\sigma_{2} / \sigma_{1}<1$; and

(iii) $a^{*}=1$ if and only if $\sigma_{2} / \sigma_{1}=1$.

Thus $\sigma_{2} / \sigma_{1}$ creates the wedge between first-best and optimal contract analysis. The intuition behind this is best understood in the simple case in which the shocks to the stochastic components of cash flows are uncorrelated $(\rho=0)$. Recall that the stock market's inference problem is to determine the period $t$ cash flow. The period $t$ cash flow is $f_{t}\left(x_{t}\right)+\theta_{t}$. Even though $x_{t}$ and $f_{t}\left(x_{t}\right)$ are unobservable, participants in the stock market can solve for the model's equilibrium and therefore know what value the manager will choose for $x_{t}$. Because $f_{t}\left(x_{t}\right)$ is a known deterministic constant, the market's inference problem is simply to determine $\theta_{t}$ from the signal $Y_{t}=f_{t}\left(x_{t}\right)+\theta_{t}+\varepsilon_{t}$. Because $f_{t}\left(x_{t}\right)$ is a known constant, it can be subtracted out from $Y_{t}$. The market is effectively trying to infer $\theta_{t}$ from $\theta_{t}+\varepsilon_{t}$. Recall that $\sigma_{t}$ is the standard deviation of $\theta_{t}$ and determines the strength of the signal in $Y_{t}$ for the market's inference problem.

Now consider the optimal contracting problem. Here the principal sets the wage contract based on a statistical aggregate designed to optimally detect any out-of-equilibrium deviations in the manager's allocations. The principal is effectively trying to determine $f_{t}\left(x_{t}\right)$ based on $Y_{t}=f_{t}\left(x_{t}\right)+\theta_{t}+\varepsilon_{t}$. In the optimal contracting problem, $\theta_{t}$ is part of noise in the inference problem and $\sigma_{t}$ determines the magnitude of this noise.

Thus $\sigma_{t}$ is a measure of noise for the contracting problem but is a measure of signal for the determination of stock valuation. (See also Paul (1992).) Note that $\sigma_{2} / \sigma_{1}>1$ causes market pricing to increase the weight on information about the long-term project but causes the optimal contract to down-weight information about the long-term project. The model is perfectly symmetric. For $\sigma_{2} / \sigma_{1}<1$, the same reasoning argues that market pricing will decrease the weight on information about the long-term project while causing the optimal contract to up-weight information about the long-term project. The relation between $\sigma_{2} / \sigma_{1}$ and 1 determines the direction of the conflicting findings from first-best and optimal contract analysis.

The region in which first-best and optimal-contracting criteria differ can be arbitrarily large. From equations (16a) and (16c), $a^{*}$ can be made arbitrarily larger than 1 by sufficiently increasing $\sigma_{2} / \sigma_{1}$ and can 
also be made arbitrarily close to zero by sufficiently decreasing $\sigma_{2} / \sigma_{1}$. From equations (16b) and (16c), $\phi^{*}$ can be made arbitrarily larger than $S$ by sufficiently increasing $\sigma_{1} / \omega_{1}$.

The following comparative statics results also obtain:

1. $d a^{*} / d \gamma>0$

2. $d a^{*} / d \eta=0$

3. $d a^{*} / d \rho<0$ for $a^{*}>1$

4. $d a^{*} / d \rho>0$ for $a^{*}<1$

5. $d a^{*} / d \rho=0$ for $a^{*}=1$,

where $\gamma=\sigma_{2} / \sigma_{1}$ and $\eta=\left(\sigma_{1} / \omega_{1}\right)^{2}$. Thus the magnitude of the difference between $a^{*}$ and 1 is increasing in $\sigma_{2} / \sigma_{1}$ for $a^{*}$ greater than one, always decreasing in $\rho$, and always unrelated to changes in $\left(\sigma_{1} / \omega_{1}\right)^{2}$.

\subsection{Perfectly Observable Cash Flows ${ }^{29}$}

By setting $\omega_{1}$ and $\omega_{2}$ to zero, the model can examine the case in which both long-term and short-term cash flows are perfectly observable. From equation (9), the ratio $\beta_{1} / \beta_{2}$ is always equal to one in this case. From equations (12a) $-(12 \mathrm{c})$, for $\rho \geq 0$ :

(i) $\alpha_{1} / \alpha_{2}>1$ if and only if $\sigma_{1}<\sigma_{2}$;

(ii) $\alpha_{1} / \alpha_{2}=1$ if and only if $\sigma_{1}=\sigma_{2} ;$ and

(iii) $\alpha_{1} / \alpha_{2}<1$ if and only if $\sigma_{1}>\sigma_{2}$.

These results provide a nice illustration of the importance of using the second-best optimum when assessing the efficiency of stock-based incentives. When cash flows are perfectly observable, the relative weight on short-term versus long-term incentives match those from first-best analysis. Nonetheless, once one takes managerial risk aversion into consideration, it turns out that these same stock-based incentives lead to myopic behavior iff $\sigma_{1}>\sigma_{2}$. In the opposite case in which $\sigma_{1}<\sigma_{2}$, they lead to excessive emphasis on the long-term. Note that the weights in the stock-based incentive contract are identical in both all three cases: $\sigma_{1}>\sigma_{2}, \sigma_{1}=\sigma_{2}$, and $\sigma_{1}<\sigma_{2}$ and always match incentives in firstbest. Nonetheless, the true efficiency of these incentives change as $\sigma_{1}$ changes relative to $\sigma_{2}$, and they change solely due to changes in the characteristics of the optimal contract.

One can also assess the extent to which myopia (or excessive emphasis on the long-term) is due to the unobservability of cash flows as opposed to the other elements of the model by first solving equations (9) and (11) for the case in which $\omega_{1}=\omega_{2}=0$ and then solving them again

29. I thank a referee for suggesting that I discuss the case in which all cash flows are completely observable. 
with $\omega_{1}$ and $\omega_{2}$ set to their actual values. A comparison of the two sets of solutions provides the effect of cash flow unobservability on the efficiency of managerial incentives.

\section{The Jensen-Stein Debate}

Jeremy Stein's 1989 critique of Jensen (1986) is perhaps the paper most responsible for launching the academic literature on managerial myopia. As such, it is worthwhile to explore the implications of the current model for the findings reported in Stein (1989). On the first page of his article, Stein takes issue with the following passage from Jensen (1986, p. 11):

Sometimes it (myopic behavior) occurs when managers (emphasis added) hold little stock in their companies and are compensated in ways that motivate them to take actions that increase accounting earnings (emphasis added) rather than the value of the firm. It also occurs when managers make mistakes because they do not understand the forces that determine stock values.

From this, Stein (1989, p. 655) concludes:

Jensen (1986, p. 11) espouses this point of view, arguing that managerial myopia will only be a problem if managers do not care enough about stock prices. This paper (Stein 1989) disputes Jensen's contention, showing that even a fully efficient market can lead managers (emphasis added) to behave myopically. Indeed the more managers (emphasis added) are concerned about current share prices, the worse the problem becomes.

In the first excerpt above, Jensen states that myopia can occur if both of the following conditions hold:

a. The firm is run by managers rather than owners.

b. Managers are compensated based on current earnings, rather than the firm's current value in the financial markets.

Stein (1989) explores neither of these conditions. In Stein (1989), the agent is effectively an owner who receives the current cash flow as income and then sells a fraction of its holdings in the firm at the current stock price and keeps the remainder of its holdings in the firm forever. In Stein (1989), the agent's payoff is current dividend $+\pi$ (current ex-div stock price)

$+(1-\pi)(P V$ of future earnings) 
- $\pi$ (current ex-div stock price) is the amount of the agent's compensation which comes from the firm's current valuation.

- $(1-\pi)$ (PV of future earnings) is the present value of the part of the agent's payoff which comes from its future stock holdings. This present value is taken with respect to the agent's information set.

These are the payoffs of an owner, not a manager. Stein examines the effect of alterations in the parameter $\pi$ and argues that, if there is a permanent component to cash flows, then myopia is increasing in the parameter $\pi$.

However, this finding has no bearing on Jensen's statement. Jensen argued that myopia can occur if managers are paid a wage contract that is solely a function of current earnings. In Stein's model, an increase in $\pi$ does not increase the importance of current stock value in compensation relative to current earnings. Instead it increases the importance of current stock value relative to the firm's future earnings (really future realized cash flows).

The benchmark in Stein (1989) is the " $\pi$ equal zero" case in which first-best efficiency is obtained by employing infinitely lived, riskneutral managers who bond themselves to the firm and thereby collect a fixed proportion of each of the firm's future cash flows as they arrive. Clearly this is not the benchmark that Jensen (1986) and others had in mind when they argued that stock-based compensation would reduce incentives for myopic behavior.

Jensen (1986) considers the relevant case in which short-lived managers run long-lived firms. Here it is not possible to pay managers based on the complete stream of the firm's future cash flows because the manager is likely to expire long before the firm. Jensen informally compared the incentives arising from compensating these managers based on current earnings to those arising from compensating them based on the current stock price.

In order to address Jensen's point, Stein would have had to examine the effects of paying managers based on current earnings versus paying them based on the firm's current stock valuation and show that myopia occurs as the firm's current stock price is given more weight in compensation relative to current earnings. A natural way to do this would have been to model managerial compensation as follows:

$k$ (current stock price) $+(1-k)$ (current earnings) $+(1-\pi)(P V$ of future cash flows) and vary the parameter $k$ for fixed levels of $\pi$.

The current paper allows us to consider the case in which the signals $Y_{1}$ and $Y_{2}$ are contractible data from accounting reports. When 
the current analysis is interpreted in this manner, it allows us to conduct the relevant comparison by comparing outcomes from compensation based on the current stock price $W(P)$ to outcomes from compensation based on an optimal contract written directly on current accounting variables $W\left(Y_{1}, Y_{2}\right)$ and shows that stock-based compensation can lead to myopic behavior relative to optimal contracts written directly on current accounting variables. The current work provides the exact conditions under which myopia occurs. ${ }^{30}$

Stein (1989) considers the case in which there is only one signal of firm value: current cash flow. In the current model, if we set $\omega_{1}$ to zero and $\omega_{2}$ to infinity, then there is only one signal of firm value and it is an exact observation of the cash flows coming from the short-term project. ${ }^{31}$ However, the results from the current model are diametrically opposed to those found in Stein (1989).

Intuitively, it is clear that both $\beta_{1} / \beta_{2}$ and $\alpha_{1} / \alpha_{2}$ are infinity when $\omega_{1}$ is equal to zero and $\omega_{2}$ to infinity. This is confirmed by equations (9) and (11). When the cash flows from the short-term project are perfectly observable and the cash flows from the long-term project are completely unobservable, both the optimal contract and stock-based incentives put complete weight on information about the short-term project and no weight on the long-term project. There is no myopia relative to the space of feasible contracts. It is impossible to compensate a short-lived manager based on the unobservable results from the long-term project. $^{32}$ But this is effectively what the first-best benchmark in Stein (1989) requires.

\section{POLICY AND EMPIRICAL IMPLICATIONS}

Recall that $a^{*}$ is the value of $\beta_{1} / \beta_{2}$ and $\alpha_{1} / \alpha_{2}$ such that $\beta_{1} / \beta_{2}=\alpha_{1} / \alpha_{2}$. From the monotonicity and single-crossing properties established in Section 5.2, the model finds myopia whenever $\beta_{1} / \beta_{2}>a^{*}$ and excessive emphasis on the long-term whenever $\beta_{1} / \beta_{2}<a^{*}$. From equations (16a) and (16c):

$$
a^{*}=\left(\frac{\gamma^{2}+\rho \gamma}{1+\rho \gamma}\right)^{(1 / 2)}
$$

30. Myopia occurs for all values of $\phi$ greater than the value given in equation (16b) in Proposition 2. Long-run projects receive excessive emphasis for all values of $\phi$ less than the value in equation (16b).

31. I thank a referee for suggesting that I use the model to examine the case in which the results from the short-term project are completely observable.

32. Also see Mello-e-Souza (1993). 
Because $\gamma$ equals $\sigma_{2} / \sigma_{1}$, this implies:

Myopia iff $\frac{\beta_{1}}{\beta_{2}}>\left(\frac{\sigma_{2}^{2}+\rho \sigma_{1} \sigma_{2}}{\sigma_{1}^{2}+\rho \sigma_{1} \sigma_{2}}\right)^{(1 / 2)}$

Excessive emphasis on long-term iff $\frac{\beta_{1}}{\beta_{2}}<\left(\frac{\sigma_{2}^{2}+\rho \sigma_{1} \sigma_{2}}{\sigma_{1}^{2}+\rho \sigma_{1} \sigma_{2}}\right)^{(1 / 2)}$.

One of the appealing features of the model is that it is amenable to empirical testing. The right-hand side of equations (17a) and (17b) only involves the volatilities of the present value of the firm's short-term and long-term cash flows and their correlation. ${ }^{33}$ It does not involve any of the characteristics of the production function $\left(f_{1}\right.$ and $\left.f_{2}\right)$ or the manager's utility function $(U(W)-V(x))$. The $\beta_{1}$ and $\beta_{2}$ values are the coefficients from a joint linear projection of current stock price on the future realized values of the cash flows from the short-term and long-term projects. Thus the ratio $\beta_{1} / \beta_{2}$ should be open to statistical estimation.

The results from Section 5 suggest that the magnitude of the inefficiencies arising from compensating managers based on the current stock price should be increasing in the absolute value of

$K=\frac{\beta_{1}}{\beta_{2}}-\left(\frac{\sigma_{2}^{2}+\rho \sigma_{1} \sigma_{2}}{\sigma_{1}^{2}+\rho \sigma_{1} \sigma_{2}}\right)^{(1 / 2)}$.

An empirical test of the model would be to see if the overall weight of the current stock price in CEO compensation is decreasing in the magnitude of $K$. Another test would be to see if the use of deferred compensation is increasing in $K$ over the subsample in which myopia is expected to occur. (This is the subsample in which $K$ is positive.)

One implication of the model is that using the current stock price to determine managerial incentives is particularly problematic for firms in which long-term cash flows are very important $\left(\sigma_{2}\right.$ is large relative to $\left.\sigma_{1}\right)$ and hard to observe ( $\omega_{2}$ is high). This phenomenon has been empirically documented. Bizjak et al. (1992) use the ratio of market value to book value and the ratio of $R \& D$ expenditures to total assets as proxies for the relative size and unpredictability of long-term cash flows. They find that CEO compensation becomes more deferred and less related to the current stock price as the proxies for the importance

33. To be more precise, it involves the volatility of the product of the stochastic discount factor with the firm's short-term cash flows and the volatility of the product of the stochastic discount factor with the firm's long-term cash flows and their correlation. 
and uncertainty of long-term cash flows increase. Kole (1997) studies the restrictions shareholders place on management compensation plans. The board of directors is prohibited from approving compensation schemes which do not meet these minimum restrictions. Kole finds that shareholders of $R \& D$ intensive firms have greater requirements for deferred compensation in that

1. The average $R \& D$ intensive firm requires restricted stock be held for a minimum of 69 months as opposed to 37 months for the rest of the sample.

2. "Hold-until-retirement plans" are rare outside of high R\&D firms.

3. $41 \%$ of high R\&D firms require restricted stock to be held until retirement as opposed to $23 \%$ of other firms.

Lerner and Wulf (2007) examine the compensation of corporate R\&D heads and find that, for companies with centralized R\&D activities, innovation measured as (i) number of patents and (ii) number of patent citations is increasing the long-term incentives of the R\&D head and unrelated to the level of its short-term compensation.

The model also predicts that firms in declining industries will generally have a greater problem with myopia while the inefficiencies in resource allocation for firms in rapidly growing industries will tend to arise from excessive emphasis on long-term projects. Consider the case in which the volatility of each period's cash flow is proportional to the scale of the firm: $\sigma_{t}=\left(\right.$ scale $\left._{t}\right) \sigma$. For a declining firm, scale is expected to decrease over time which implies $\sigma_{2}<\sigma_{1}$. For a expanding firm, scale $t_{t}$ is expected to increase over time which implies $\sigma_{2}>\sigma_{1}$.

In the current model $a^{*}$ converges to zero and $\beta_{1} / \beta_{2}$ approaches infinity as $\sigma_{2} / \sigma_{1}$ goes to zero. Thus myopia should be a problem for firms in severe decline. On the other hand, $a^{*}$ approaches infinity and $\beta_{1} / \beta_{2}$ converges to zero as $\sigma_{2} / \sigma_{1}$ goes to infinity. Thus excessive emphasis on the long-term should be a problem for firms which are expected to grow rapidly. Several commentators in the business press have argued that this second effect occurred to many "dotcom" Internet firms in the late 1990s.

These empirical implications can also be viewed as policy recommendations. Although it is not clear that the model suggests any increased role for regulation, it does indicate situations in which compensation committees and compensation consultants should be especially wary of reliance on current stock valuation. If the firm feels that its best alternative is to stress current stock valuation in compensation, then equations (17a) and (17b) provide guidance as to the nature of the inefficiencies which may result and which the firm may try to ameliorate through other controls. 
A final policy implication is that policy makers, academics, and outside analysts should exercise caution before asserting that stockbased compensation has resulted in myopic incentives. Typically, shortterm projects involve less risk than long-term projects. Thus optimal contracting, in almost any situation, will tend to favor short-term projects relative to a first-best standard, making it imperative to use the proper second-best standard before advocating any restrictions on the use of current stock valuations in compensation.

\section{Literature REVIEW}

\subsection{OVERVIEW}

Narayanan (1985) and Stein (1989) have used Harris and Holmstrom (1982) and Holmstrom (1982) "signal-jamming" models to show that the manager may move cash forward to boost the market's assessment of the permanent component of future cash flows generated by the firm or the manager. ${ }^{34}$ Narayanan (1985) and Stein (1989) both emphasize that myopic incentives are directly related to the permanence of cash flow shocks. ${ }^{35}$ In Narayanan (1985) myopia does not occur if there is no permanent component to cash flow. In Stein (1989) the stock price becomes a fixed constant which does not reflect future earnings in the case in which there is no permanent component to cash flows. ${ }^{36}$ In this case stock compensation becomes equivalent to earnings-based compensation and inherits its inefficiencies including incentives for myopic behavior. When there is no permanent component to earnings, stock-based compensation does not generate any extra myopia in Stein (1989) above that which would have been generated by earnings-based compensation.

By contrast, the permanence of cash flow shocks in the current paper $(\rho)$ is not a major determinant of myopia. In the current model, the current stock price contains information about future cash flows even when cash flows are uncorrelated over time. It finds that, even in the case in which there is no permanent component to cash flow,

34. Campbell and Marino (1994) verifies that the key results from Narayanan (1985) hold when there are lower bounds on the individual payments that can be made to the manager.

35. The persistence parameter in Stein (1989) is $k$ which equals $\rho /(1-\rho)$, where $\rho$ is the intertemporal correlation of cash flows.

36. In Stein (1989), current earnings are paid out as a dividend and the stock price used in the model is the ex-dividend stock price. Thus the stock price in Stein does not reflect current earnings but instead is the present value of the firm's expected future cash flows. This expectation is a constant in Stein (1989) in the cash in which there is no permanent component to earnings. 
firms will in general have inefficient intertemporal incentives. Our findings emphasize the importance of the signal-to-noise ratios of the market's signals of future cash flows. When the relative size of these signal-to-noise ratios gets sufficiently large, the manager will overemphasize the project associated with the highest signal-to-noise ratio.

When they do find inefficiencies, Narayanan (1985) and Stein (1989) only find myopia. Our model finds that it is also possible for excessive emphasis to be placed on long-term projects and gives the exact conditions under which this will occur. Similarly, Bebchuk and Stole (1993) only find myopia in the case considered here in which the marginal productivity of investment is known.

Milgrom and Roberts (1992) use a model very similar to that presented in Sections 2 and 3 to discuss stock-induced myopia. ${ }^{37}$ However, they compare stock-based incentives to first-best incentives in evaluating whether stock incentives generate myopic behavior. As our work emphasizes, conclusions based on first-best efficiency are often reversed when the proper second-best criteria is used to judge the effects of stock compensation on intertemporal incentives.

Like the current model, Bebchuk and Stole (1993) and Bizjak et al. (1993) find conditions under which long-term projects will be overemphasized. Bebchuk and Stole (1993) finds that myopia occurs when the level of investment is unobservable but that excessive emphasis on the long term occurs when the marginal productivity of investment is unobservable. Bizjak et al. (1993) consider an environment in which the decision to invest is observable to outsiders but project NPV is not. They show that stock compensation can create pooling equilibria. If the average project in the pool has negative NPV, then, in the pooling equilibrium, even firms with positive NPV projects choose not to firms invest (myopia). If the average project in the pool has positive NPV, then all firms invest (even those with negative NPV projects) leading to excessive creation of long-term cash flows. ${ }^{38}$

Von Thadden (1995) considers external debt financing and shows that there may be conditions in which short-term debt financing is optimal and induces the firm to favor short-term projects over

37. See pp. $471-473$.

38. Although their model does not address myopia itself, the findings in Brandenberger and Polak (1996) are in the same spirit as Bizjak et al. Brandenberger and Polak (1996) present a signaling model which points out inefficiencies that can arise when managers care only about their current stock price. They show that if the manager's information set strictly dominates that of the market, management ignore the part of its information that is not observable to the market when taking actions that the market can observe. 
long-term projects, even if the long-term projects have higher overall value. Von Thadden's model treats situations in which agents lacking private information (such as debtholders) can terminate projects early when preliminary results indicate poor profitability.

Thakor (1990) considers a situation in which the firm has superior information about its value relative to outside investors, causing outside investors to demand a premium when purchasing newly-issued securities. Thakor (1990) points out that this causes the firm to face a cost of capital that is higher than the symmetric information cost of capital and leads the firm to favor projects which generate cash quickly. Thakor (1993) establishes equilibria in which firms signal that their securities are undervalued by investing in short-term projects and, thereby, demonstrating to the market that they would rather invest myopically than issue securities at their current (low) market price. In Stein (1988) the value of the firm's assets is unobservable until they are liquidated. If firms are motivated solely by their current stock price, good firms will have an incentive to liquidate their assets early to reveal their value.

Narayanan (1996) reverses these effects by examining compensation packages that are composed of a mix of cash and stock where the total market value of the compensation package must equal the manager's reservation wage as set by the labor market's perceptions of the manager's ability. Here two effects interact. The first effect is the source of myopia in Narayanan (1985): The manager has an incentive to unobservably move cash forward to enhance the labor market's perception of managerial ability and, thereby, increase the market value of the compensation package. On the other hand, for any given compensation package market value, the percentage of the firm given to the manager is decreasing in the stock price. This generates a second somewhat offsetting effect which leads the manager to take actions that reduce the current stock price (and boost the future stock price). In Narayanan (1996) optimal contracting balances these two effects to minimize investment distortions.

None of the papers described in this section allow for risk aversion or judge the efficiency of stock incentives relative to a second-best standard based on optimal contracting.

In a recent paper Bolton et al. (2006) do consider risk averse managers but do not allow for optimal contracting. Bolton, Scheinkman and Xiong remind us that myopia can occur in when stock markets are not efficient and point out that current shareholders may favor shorttermism because they may benefit indirectly from the firm's ability to raise additional capital at inflated prices. 


\subsection{Relevance for the policy Debate}

The policy debate over managerial myopia is not whether corporate decision making obtains a first-best resource allocation between shortterm and long-term projects. Clearly, it does not. The corporate form is a response to a variety of market imperfections. Each one of which is likely to impinge somewhat on the firm's intertemporal allocation of resources.

The policy debate instead centers on whether stock market pressures cause short-termism and whether increased focus on the current stock price increases short-termism. ${ }^{39}$ Indeed none of the proposed remedies that I am aware of for managerial myopia address possible sources of corporate myopia other than those induced by the stock market, such as labor market signaling. Thus, in many ways, the broad question of "does myopia occur" is less relevant than the question addressed in this paper: "Do incentives based on the current stock price lead to myopic behavior?"

A number of papers have established that imperfections in the managerial labor market can cause myopia relative to a first-best standard. The myopia in these papers is caused by the labor market, not the stock market, and would continue to hold for a private firm that did not have publicly traded stock. ${ }^{40}$ Thus this sub-literature, while important for understanding labor market issues, has no bearing on policy debates regarding the effects of the stock market on firm operations.

One of the central policy questions that generated the myopia literature was a desire to understand the extent to which decentralized publicly-traded equity markets such as those that predominate in the United States result in myopia or, more generally, inferior investment behavior relative to the Japanese system in which large firms typically have access to sizeable internal capital markets and can essentially be viewed as subsidiaries of a parent holding group that itself is almost completely insulated from stock market pressure.

Any model of myopia that applies with equal force to firms that finance projects from internal capital markets has limited relevance for this debate. This should be taken into consideration when evaluating the signaling and signal-jamming models described in the previous

39. Edlin and Stiglitz (1995) take a different perspective on this debate. They show that managers have an incentive to overinvest in projects that increase their bargaining power relative to the owners of the firm. Edlin and Stiglitz argue that the extent of these sorts of inefficient investments may be reduced to the extent that myopia gives managers a somewhat counterbalancing incentive to underinvest.

40. Some important examples are Mello-e-Souza (1993), Campbell and Marino (1994), Noe and Rebello (1997), and Hirshleifer et al. (2001). 
literature review. ${ }^{41}$ These models also apply to a manager of a subsidiary requesting capital from a parent firm or holding firm structure. Here, the manager of the subsidiary will be at an informational advantage relative to the headquarters of the parent firm and may wish to (i) liquidate good related projects early an in Stein (1988) to prove their profitability; (ii) underinvest to indicate high profitability when investment is unobservable as in Stein (1989) and Bebchuk and Stole (1993) or when the project pools with negative NPV projects as in Bizjak et al. (1993); and (iii) overinvest to signal high profitability when the marginal productivity of investment is unobservable as in Bebchuk and Stole (1993) or when the project pools with positive NPV projects as in Bizjak et al. (1993) and so on.

Similarly, Von Thadden (1995) also applies to privately-held firms in which projects are funded completely from internal capital and in which corporate headquarters has the ability to terminate project funding upon the receipt of poor preliminary results. Here lower-level managers with access to superior information may choose to act myopically to prevent cut-off of central funding. Their actions would induce myopia in overall outcomes, even though the firm has no exposure to the public markets. ${ }^{42}$

To be fair, the use of internal capital markets may mitigate some of these issues to the extent that the parent holding group or headquarters can extract information from subsidiaries that is more reliable than the disclosures available to decentralized investors. These models comment on the relative advantages of internal versus external capital markets regarding myopia only to the extent that internal communication flows in internal capital market are superior to the information received by investors in publicly-traded firms. Analysis of the costs, benefits, and effectiveness of internal communication channels, however, is missing from the papers in this literature. It is not clear that internal capital markets dominate decentralized capital markets in this regard. Holmstrom and Tirole (1993), for example, stresses the monitoring advantages that come from publicly-traded stock.

By contrast, the role of the stock market is crucial in the current model. In the case in which the signals $Y_{1}$ and $Y_{2}$ are not observable by the firm, the firm's publicly-traded price provides a mechanism to obtain this information in contractible form. Suppose instead the firm is private.

41. Other than Thakor (1991) and Thakor (1993).

42. Many of the proposed remedies for stock-market induced myopia such as transaction taxes would entail high costs for equity capital. To the extent that equity financing becomes more costly, firms are likely to substitute out equity financing into debt financing. However, Von Thadden's work suggests that some of this new debt would likely be shortterm debt which can also induce myopic behavior. 
In this case the firm's stock is not traded and the stock price cannot be observed. Instead the owners of the firm have no recourse but to value the firm based on their own information. Here those who provide capital to the firm only have access to their own private information set, perhaps augmented by the signaling processes described in the other papers in this literature. They have no ability to indirectly access the information privately observed by third parties that would have been reflected in prices from public stock trading in secondary markets.

If instead the firm is a subsidiary, the story is the same. Now the providers of capital can only access the information observed by others to the extent that it is reflected in the parent firm's stock price. However, for an internal capital market to be a meaningful alternative to external capital markets, it has to be the case that the subsidiary's prospects are a trivial determinant of the price of the parent firm. To the extent that the parent has publicly traded stock and its stock price is completely driven by the prospects of the subsidiary, the economically relevant case is external capital markets.

\section{CONCLUSION}

Because managers are risk averse, there is an advantage to downweighting the importance of high volatility signals and up-weighting the importance of low volatility signals in managerial compensation. In the standard case in which the market's information about nearterm cash flows is less variable than its information about long-term cash flows, optimal contracting will naturally place more emphasis on near-term cash flows relative to overall firm value. Before one can conclude that stock-based incentives lead to myopic behavior, one has to determine whether the stress given to short-term projects is greater than it would be under optimal contracting. If not, the "myopia" is due to agency issues, not stock compensation. Despite the large number of important papers devoted to myopia, the significance of risk aversion in setting intertemporal incentives has not been addressed by the literature.

This paper shows that one cannot rely on myopia findings relative to first-best incentives to continue to hold relative to the relevant optimal contracting criterion. The ratio $\sigma_{1} / \omega_{1}$ is the signal-to-noise ratio of the market's information about the cash flows from the short-term project. Similarly, $\sigma_{2} / \omega_{2}$ is the signal-to-noise ratio of the market's information about the cash flows from the long-term project. The manager's incentive to stress the short-term project over the long-term project is linear in the square of the ratio of these signal-to-noise ratios: $\left[\left(\sigma_{1} / \omega_{1}\right) /\left(\sigma_{2} / \omega_{2}\right)\right]^{2}$. This ratio determines the relative informativeness of 
the market's short-term versus long-term signals in determining firm value and is a natural measure to use to parameterize the market's information. The paper shows that there can be an arbitrarily large range of values of $\left[\left(\sigma_{1} / \omega_{1}\right) /\left(\sigma_{2} / \omega_{2}\right)\right]^{2}$ in which optimal contracting and first-best standards come to differing conclusions in regard to whether equilibrium incentives result in myopia. This paper solves for the exact parameters in which the conclusions relative to a first-best standard are reversed when evaluated relative to the relevant second-best standard.

Alternatively, one can directly examine the relative weight placed on short-term projects versus long-term projects in managerial compensation. The paper finds that there can be an arbitrarily large range of equilibrium incentive weights which are myopic by first-best standards but not myopic when judged relative to optimal contracting incentives. The size of this region is determined by the ratio of the volatility of the long-run cash flow divided by the volatility of the short run cash flow $\left(\sigma_{2} / \sigma_{1}\right)$.

If $\sigma_{2} / \sigma_{1}>1$, then, in the region in which first-best and optimal contracting analysis differ, the first-best criteria mistakenly concludes that stock incentives have caused myopic behavior when, in actuality, stock-based incentives generate excessive emphasis on the long-term project. In this case the principal-agent problem is inducing myopia, not the stock-based incentives. Although stock-based incentives help move the agent's allocation of the unobservable resource closer to the first-best level, they nonetheless reduce both overall welfare and firm value, by placing excessive risk on the manager relative to what would occur in an optimal contract. This excessive risk requires the principal to pay an excessive risk premium to the manager. The extra risk premium required by the manager more than offsets the added value that comes from having the unobservable allocation move closer to first-best.

If $\sigma_{2} / \sigma_{1}<1$, then, in the region in which first-best and optimal contracting analysis differ, the first-best criteria mistakenly concludes that stock incentives have caused excessive emphasis on the long-term project when in actuality stock-based incentives have induced myopia. Now it is the principal-agent problem that causes excessive concern for the long-term, not the stock-based incentives. As in the previous case, the benefit that stock-based incentives provide by moving the agent's allocation closer to first-best is not sufficient to overcome the loss in value due to diminished risk-sharing.

Paul (1992) establishes that $\sigma$ is part of the "noise" for the contracting problem but is part of the "signal" for the determination of stock valuation. For $\sigma_{2} / \sigma_{1}>1$, the $\sigma_{2} / \sigma_{1}$ ratio causes market pricing to up-weight information about the long-term project but causes the 
optimal contract to reduce the weight given to information about the long-term project. Similarly, for $\sigma_{2} / \sigma_{1}<1$, the same reasoning shows that the $\sigma_{2} / \sigma_{1}$ ratio causes market pricing to reduce the weight given to information about the long-term project while causing the optimal contract to up-weight information about the long-term project. These conflicting effects generate the wedge between first-best and optimal contracting analysis.

Paul (1992) requires a Holmstrom-Milgrom (1987) environment to ensure that linear contracts are optimal and solves for the optimal contract in the space of linear contracts. The current analysis shows how the methods developed in Banker and Datar (1989) can be used to extend the results in Paul (1992) to settings in which nonlinear contracts may be optimal.

It would have seemed reasonable to assume that judging myopia results relative to a second-best optimal contracting standard, rather than first-best, is a technical point which would have a trivial effect on overall results. However, this paper shows that moving from an irrelevant first-best standard to the proper second-best standard often reverses conclusions. The paper shows that what is presented in Milgrom and Robert (1992) as myopia is often, in reality, excessive emphasis on the long-term. This is a dramatic reversal. It also shows that the results in Stein (1989) change from myopia to optimality when incentives are evaluated relative to an optimal-contracting standard.

Other papers in the myopia literature models are harder to map into the present framework. However, the current work suggests that their results are highly sensitive to the use of risk-neutral managers judged relative to a first-best standard: Typically, short-term projects involve less risk than long-term projects. Thus optimal contracting in almost any situation will tend to favor them relative to a first-best standard, making it imperative to use the proper second-best standard before drawing conclusions about myopia. Although the previous literature may have employed risk-neutral managers and a first-best standard as simplifying assumptions, one must be cautious drawing inferences from models where simplifying assumptions have the power to dramatically change results.

\section{APpendix}

Proof of Proposition 1. From equation (8), $\alpha_{1} f_{1}^{\prime}=\alpha_{2} f_{2}^{\prime}$ at the second-best. Substituting $f_{2}^{\prime}=\frac{\alpha_{1}}{\alpha_{2}} f_{1}^{\prime}$ into equation (10) results in equation (11). By inspection, the solution to equation (11) exists and is unique for $\kappa=0$. All that remains is to establish that there is a unique positive solution for $\kappa>0$. The remainder of the proof considers the case in which $\kappa>0$. 
Define $h(z)=z^{3}+\kappa z^{2}-\kappa z-m$ where $m=\operatorname{Var}\left(Y_{2}\right) / \operatorname{Var}\left(Y_{1}\right)$.

Observation 1: $h(0)<0$.

Observation 2: $h$ approaches $+\infty$ as $z$ approaches $+\infty$.

Observation 3: A positive real solution to equation (11) exists.

Proof of Observation 3. From Observations 1, 2 and the continuity of $h$, there must be a solution to equation (11) which is greater than 0 .

All that remains is to show that this positive real solution is unique.

Observation 4: $h^{\prime}(0)<0$.

Observation 5: $h^{\prime}(z)=3 z^{2}+2 \kappa z-\kappa$.

Observation 6: $h^{\prime}(z)$ changes sign no more than once for $z$ positive.

Proof of Observation 6. For $\kappa>0$, there is only one positive solution to $3 z^{2}$ $+2 \kappa z-\kappa=0$. Because $h^{\prime}(z)=3 z^{2}+2 \kappa z-\kappa$ is a quadratic polynomial, Observation 6 follows.

Remainder of Proof. Observations 1, 4, and 3 state $h(0)<0, h^{\prime}(0)<0$ and that a positive solution to $h(z)=0$ exists. This implies that $h^{\prime}(z)$ must change signs between $z=0$ and the positive solution to $h(z)=0$. From Observation $6, h^{\prime}(z)$ can never subsequently change its sign. Therefore, once $h(z)$ crosses 0 , for positive $z$, it can never cross again. The positive solution is unique.

The notation and observations established in the proof of Proposition 1 can be used to verify that a positive real solution to equation (11) exists in the case $\rho<0$. Note that $h(0)$ is negative but that $h(z)$ is positive for $z$ sufficiently large. By continuity $h(z)$ must equal 0 for some value of $z$ greater than 0 . This establishes the existence of a positive real solution for all values of $\rho$. However, uniqueness of the positive real solution is only established for $\rho \geq 0$.

Proof that $\rho \geq 0$ implies that $d a / d \phi>0$.

From equation (15) if $a(\phi)$ is not increasing in $\phi$, then $3 a^{2}+2 \kappa a-$ $\kappa<0$ which implies

$a<\frac{-2 \kappa+\sqrt{4 \kappa^{2}+12 \kappa}}{6}$

( $\rho \geq 0$ implies $\kappa \geq 0$. Because $a$ cannot be negative, only the " + " root is relevant.) 
However, equation (11) implies $a^{3}+\kappa a^{2}>\kappa a$. Because $a>0$, this implies $a^{2}+\kappa a-\kappa>0$ which implies

$a>\frac{-\kappa+\sqrt{\kappa^{2}+4 \kappa}}{2}=\frac{-2 \kappa+\sqrt{4 \kappa^{2}+16 \kappa}}{4}$.

( $\rho \geq 0$ implies $\kappa \geq 0$. Because $a$ cannot be negative, only the " + " root is relevant.)

But this contradicts Inequality (A1). So $3 a^{2}+2 \kappa a-\kappa$ cannot be negative and $a(\phi)$ is always increasing in $\phi$.

Proof of Proposition 2. A positive number $b$ equals $\beta_{1} / \beta_{2}$ and $\alpha_{1} / \alpha_{2}$ if and only if it satisfies equations (14a) and (11). Therefore, $b$ must satisfy both of the following:

$b^{3}+\kappa b^{2}-\kappa b-\frac{\operatorname{Var}\left(Y_{2}\right)}{\operatorname{Var}\left(Y_{1}\right)}=0$

and

$b=Q+R \phi$.

Note that

$\frac{\operatorname{Var}\left(Y_{2}\right)}{\operatorname{Var}\left(Y_{1}\right)}=\frac{\gamma^{2}(\eta+\phi)}{1+\eta}$.

Substituting this expression into equation (A2a) implies $b$ equals $\beta_{1} / \beta_{2}$ and $\alpha_{1} / \alpha_{2}$ if and only if $b$ satisfies equations (A2b) and (A3) below:

$b^{3}+\kappa b^{2}-\kappa b-\frac{\gamma^{2}(\eta+\phi)}{1+\eta}=0$

From equation (A2b), $\phi=\frac{b-Q}{R}=\frac{b}{R}-\frac{\left(1-\rho^{2}\right) \eta}{1+\rho \gamma}$. Substituting this into equation (A3) implies that $b$ equals $\beta_{1} / \beta_{2}$ and $\alpha_{1} / \alpha_{2}$ if and only if $b$ satisfies

$b^{3}+\kappa b^{2}-\left[\kappa+\frac{\gamma^{2}}{(1+\eta) R}\right] b-\frac{\gamma^{2} \eta}{1+\eta}\left[1-\frac{1-\rho^{2}}{1+\rho \gamma}\right]=0$.

The constants $R$ and $\kappa$ are unrelated to $\phi .\left(\kappa=\frac{\rho \gamma \eta}{1+\eta}\right)$. Note that $b=$ $\gamma S^{1 / 2}$ satisfies equation (A4). ${ }^{43}$ Substituting $b=\gamma S^{1 / 2}$ into $\phi=(b-Q) / R$ yields the expression for $\phi$ provided in equation (16b). ${ }^{44}$ All that remains is to show that the positive value of $b$ that satisfies equation (A4) is unique. The remainder of the proof is very similar to the demonstration of uniqueness in the proof of Proposition 1.

43. The algebra is available from the author upon request.

44. The algebra is available from the author upon request. 
Define $h(z)=z^{3}+\kappa z^{2}-p z-m$ where $p$ and $m$ are the following constants:

$p=\kappa+\frac{\gamma^{2}}{(1+\eta) R}$ and $m=\frac{\gamma^{2} \eta}{1+\eta}\left[1-\frac{1-\rho^{2}}{1+\rho \gamma}\right]$. Recall $\kappa=\frac{\rho \gamma \eta}{1+\eta}$.

Consider the case in which $\rho=0$ or $\eta=0$. In this case, $\kappa=0$ and $m=$ 0 and equation (A4) reduces to $b^{3}-\left[\frac{\gamma^{2}}{(1+\eta) R}\right] b=0$ which has the unique positive solution $b=\frac{\gamma}{(1+\eta)^{1 / 2} R^{1 / 2}}$. The remainder of the proof considers the case in which both $\rho>0$ and $\eta>0$.

Observation 1: Because both $\rho>0$ and $\eta>0$, the constants $\kappa, p$, and $m$ are strictly positive.

Observation 2: $h(0)<0$.

Observation 3: A positive real solution exists. (The solution given in equations (16a and 16c) has already been established.)

Observation 4: $h^{\prime}(0)<0$.

Observation 5: $h^{\prime}(z)=3 z^{2}+2 \kappa z-p$.

Observation 6: $h^{\prime}(z)$ changes sign no more than once for $z$ positive.

Proof of Observation 6. Given $\kappa>0$ and $p>0$, there is only one positive solution to $3 z^{2}+2 \kappa z-p=0$. Observation 6 follows from the fact that $h^{\prime}(\mathrm{z})$ is a quadratic polynomial.

Remainder of Proof. Observations 2, 4, and 3 state $h(0)<0, h^{\prime}(0)<0$ and that a positive solution to $h(z)=0$ exists. This implies that $h^{\prime}(z)$ must change signs between $z=0$ and the positive solution to $h(z)=0$. From Observation $6, h^{\prime}(\mathrm{z})$ can never subsequently change its sign. Therefore, once $h(z)$ crosses 0 , for positive $z$, it can never cross again. The positive solution to equation (A4) is unique.

\section{REFERENCES}

Banker, R. and S. Datar, 1989, "Sensitivity, Precision, and Linear Aggregation of Signals for Performance Evaluation," Journal of Accounting Research, 27, 21-39.

Bebchuk, L.A. and L.A. Stole, 1993, "Do Short-Term Objectives Lead to Under- or OverInvestment in Long-Term Projects?," Journal of Finance, 48, 719-729.

Bizjak, J., J. Brickley, and J. Coles, 1993, “Stock-Based Incentive Compensation, Asymmetric Information, and Investment Behavior," Journal of Accounting and Economics, 16, 349372.

Bolton, P., J. Scheinkman, and W. Xiong, 2006, “Executive Compensation and Short-Termist Behavior in Speculative Markets," Review of Economic Studies, 73, 577-610. 
Brandenberger, A. and B. Polak, 1996, “When Managers Cover their Posteriors: Making The Decisions THE Market Wants to See," RAND Journal of Economics, 27, 523-541.

Bresnahan, T., P. Milgrom, and J. Paul, 1992, "The Real Output of the Stock Exchange," in Z. Griliches, ed., Output Measurement in the Services Sector, Chicago, University of Chicago Press (for the NBER), 195-216.

Campbell, T. and A. Marino, 1994, “Myopic Investment Decisions and Competitive Labor Markets," International Economic Review, 35, 855-875.

Edlin, A. and J. Stiglitz, 1995, "Managerial Rent-Seeking and Economic Inefficiencies," American Economic Review, 85, 1301-1312.

Harris, M. and B. Holmstrom, 1982, "A Theory of Wage Dynamics," Review ofEconomic Studies, 49, 315-333.

Holmstrom, B., 1982, “Managerial Incentive Problems: A Dynamic Perspective," in Essays in Economics and Management in Honor of Lars Wahlbeck, Helsinki: Swedish School of Economics

— Incentives," Econometrica, 55, 303-328.

— and J. Tirole, 1993, "Market Liquidity and Performance Monitoring," Journal of Political Economy, 101, 678-709.

Hirshleifer, D., T. Chordia, and S. Lim, 2001, “Firm and Managerial Incentives to Manipulate the Timing of Project Resolution," Working Paper.

Jensen, M., 1986, "The Takeover Controversy: Analysis and Evidence," Midland Corporate Finance Journal, 4, 6-32.

Jewitt, I., 1988, "Justifying the First-Order Approach to Principal-Agent Problems," Econometrica, 56, 1177-1190.

Kole, S., 1997, "The Complexity of Compensation Contracts," Journal of Financial Economics, $48,79-104$.

Lerner, J. and J. Wulf, 2007, "Innovation and Incentives: Evidence from Corporate R\&D," Review of Economics and Statistics, 89, 634-644.

Mello-e-Souza, C.A., 1993, "Mortal Managers and Long-Term Goals: An Impossibility Result," RAND Journal of Economics, 93, 313-327.

Milgrom, P. and J. Roberts, 1992, Economics, Organization \& Management, Englewood Cliffs, NY: Prentice-Hall.

Narayanan, M.P., 1985, “Managerial Incentives for Short-Term Results," Journal of Finance, 40, 1469-1484.

— , 1996, "Forms of Compensation and Managerial Decision Horizon," Journal of Financial and Quantitative Analysis, 31, 467-491.

Noe, T. and M. Rebello, 1997, "Renegotiation, Investment Horizons, and Managerial Discretion," Journal of Business, 70, 385-407.

Paul, J., 1992, "On the Efficiency of Stock-Based Compensation," Review of Financial Studies, $5,471-502$.

Raiffa, H. and R. Schlaifer, 1961, Applied Statistical Decision Theory, Graduate School of Business, Boston, Harvard University.

Stein, J., 1988, “Takeover Threats and Managerial Myopia," Journal of Political Economy, 96, 61-80.

— 1989 , "Efficient Capital Markets, Inefficient Firms: A Model of Myopic Corporate Behavior," Quarterly Journal of Economics, 104, 655-669.

Thakor, A., 1990, "Investment 'Myopia' and the Internal Organization of Capital Allocation Decisions," Journal of Law, Economics, and Organization, 6, 129-154.

- 1993, "Information, Investment Horizon, and Price Reactions," Journal of Financial and Quantitative Analysis, 28, 459-482.

Von Thadden, E.-L., 1995, “Long-term Contracts, Short-Term Investment and Monitoring," Review of Economic Studies, 62, 557-575. 